\title{
A 2D Curvilinear Coupled Surface-Subsurface flow model for simulation of basin/border irrigation: theory, validation and application
}

Seyed Mohammadreza Naghedifar ${ }^{1}$, Ali Naghi Ziaei ${ }^{1}$, Enrique Playán ${ }^{2}$, Nery Zapata ${ }^{2}$, Hossein Ansari ${ }^{1}$, Seyed Majid Hasheminia ${ }^{1}$

\section{Introduction}

After millennia of surface irrigation practice, this irrigation system continues to interest researchers owing to its low operation and maintenance costs and its high potential of application efficiency, similar to that of any other irrigation system (Clemmens 1994). Efficient surface irrigation systems require proper design and management. During the last two decades of the $20^{\text {th }}$ century, numerical simulation models emerged as critical tools for surface irrigation design and management, due to their convenience, accuracy and computational speed.

A wide range of numerical models have been proposed for the simulation of basin/border irrigation. From the standpoint of the governing equations solved in these models, changes have been relevant. Researchers started solving simplified versions of the one dimensional Saint-Venant equations, i.e. kinematic wave (e.g. Walker and Humpherys 1983) and diffusion wave (e.g. Clemmens 1979; Strelkoff and Souza 1984; Schmitz and Seus 1989) approximations. These simulation efforts are based on the use of empirical infiltration equations. In a clear precedent to this paper, Dong et al. (2013) presented an implicit Crank-Nicolson, finite volume coupled solution of one dimensional Saint-Venant and two dimensional Richards’ infiltration equation.

The two dimensional Saint-Venant equations have been addressed in the last three decades (Playán et al. 1994a, b; Khanna et al. 2003a, b; Strelkoff et al. 2003; Xu et al. 2013; Zhang et al. 2014a). In this century, the zero-inertia and full hydrodynamic forms of the Saint-Venant equations have been frequently used in two dimensional surface irrigation models (Brufau et al. 2002; Zhang et al. 2014b, c, Zhang et al. 2016). Two dimensional simulation permits to overcome a number of problems related to one dimensional models. Among them, irregular field geometries or the spatial variability of key irrigation variables.

Recently, Zhang et al. (2014b) developed a finite volume model of the two dimensional Saint-Venant equations based on the diffusion wave approximation for application to basin irrigation. They compared the performance of their model with the results obtained by the complete hydrodynamic solution of the Saint-Venant equations. These authors reported that despite the adopted simplifications (disregarding local and convective acceleration terms in the momentum equations), results could be successfully compared to those produced with a full hydrodynamic model. Moreover, the diffusion form of the Saint-Venant equations led to a high level of computational efficiency due to its relatively simple nature.

Subsurface flow (infiltration) in surface irrigation models has traditionally been simulated using empirical equations such as the Kostiakov or Kostiakov-Lewis equations (e.g. Clemmens 1979; Playán et al. 1994a; Playán et al. 1996; Singh and Bhallamudi 1997; Zhang et al. 2014c; Zhang et al. 2016). These equations have proven convenient due to their simplicity in calibration and programming. However, Kostiakov parameters are only valid at the time and location of their measurement (Khanna and Malano 2006). Moreover, empirical infiltration equations only act as a water sink, and cannot simulate water redistribution within the unsaturated zone. To address such deficiencies, researchers have explored the use of Richards' equation (Zerihun et al. 2005a, b; Bautista et al. 2010) in combination with the Saint-Venant equations. Richards' equation can provide estimates of the spatial distribution of soil water content, and it only requires measurements of specific soil water parameters. Among the common forms of Richards' equation, the mixed form has proven preferable to the water content-based and

\footnotetext{
${ }^{1}$ Department of Water Science and Engineering, Ferdowsi University of Mashhad (FUM), Mashhad, Islamic Republic of Iran.

2 Department of Soil and Water, Estación Experimental Aula Dei (EEAD), CSIC, Av. Montanana 1005, 50059 Zaragoza, Spain.
} 
pressure-based forms. This preference responds to the fact that, during a surface irrigation event, the key driving force in soil water is pressure gradient, not water content gradient. Hence, the water content-based form of Richards' equation shows limitations in layered soils (Šimůnek 2005). On the other hand, the water capacity function $\left(C_{w}=\partial \theta / \partial \psi\right)$ can induce large mass balance errors in the pressure-based form of Richards' equation (Celia et al. 1990) due to its highly non-linear nature.

In order to illustrate the problems related to the use of calibration-dependent empirical infiltration equations, Zerihun et al. (2005a) proposed two numerical models for simulation of basin irrigation. In both models, overland flow was governed by a zero-inertia form of the one dimensional Saint-Venant equations. Infiltration was simulated through: a) the one dimensional Richards' equation; and b) the empirical Kostiakov equation. In both models, cumulative infiltration at the time of recession at a point $85 \mathrm{~m}$ downstream from the inlet was tracked and compared. A significant difference in cumulative infiltration was found between both models. Zerihun et al. (2005a) attributed this difference to the calibration process, since the Kostiakov-based model was only calibrated with advance data.

Khanna and Malano (2006) reviewed several basin irrigation models in the literature. They concluded that two dimensional models had higher capabilities than one dimensional models. Furthermore, these authors reported that the inclusion of micro topography (soil undulations) could improve the accuracy of simulations. Zapata and Playán (2000) simulated the advance phase of four irrigation events applied on a laser-leveled experimental basin and compared their results with observed data. They showed that by neglecting the effect of soil undulations on water movement, the RMSE of advance phase trajectories with respect to observed data for four irrigations was about 21.9, 26.2, 29.4 and 28.0\% (percentage of the basin area covered by water), while it was reduced to 13.8, 19.9, 20.8 and 15.9\% when the effect of micro topography was taken into account. Khanna and Malano (2006) based their conclusion on the work of Playán et al. (1996), who incorporated micro topography in a two dimensional basin irrigation model. Further, Zapata and Playán (2000) reported that the inclusion of micro topography improves the predictive capacity of the models even if laser leveling is used. On the other hand, many irrigation basins are characterized by irregular layouts (Singh and Bhallamudi 1997; Khanna et al. 2003b), or are irrigated by point inflows. These situations are best simulated with two dimensional models.

From the viewpoint of numerical cost, An et al. (2010) (Test case 4, Section 4.4) compared the efficiency of non-orthogonal and high resolution stepwise grids for the simulation of the rainfall-runoff problem on a slope in a three dimensional curvilinear domain using Richards' equation. Their results showed that the curvilinear model required about seven times lower grid resolution and 15 times less CPU time. Furthermore, using a curvilinear model, the mass balance error was reduced from $0.48 \%$ to $0.25 \%$.

In order to contribute to overcome the aforementioned problems in surface irrigation modeling, in this study, a simulation model for basin/border irrigation is presented. The model is based on the two dimensional Saint-Venant equations with a diffusion wave approximation. Overland hydraulics are coupled to the three dimensional mixedform of Richards' equation. Both overland and subsurface equations are discretized with an underrelaxed finite volume approach. The coordinate transformation technique was applied to improve the capability of model for simulating water flow on irregular layouts or undulated topographies. Technical aspects of the proposed model, such as numerical discretization, coordinate transformation approach and coupling method are illustrated in the following sections. Finally, several test cases extracted from the literature are used to validate the proposed model.

\section{Materials and Methods}

\subsection{Saturated-Unsaturated subsurface flow}

Saturated-unsaturated subsurface flow is governed by Richards' equation (Richards 1931), whose mixed form is described as, 


$$
\frac{\partial \theta}{\partial t}-\vec{\nabla} \cdot(K(\psi) \vec{\nabla}(\psi+\mathrm{Z}))=q_{s u b, e}
$$

Where $\theta$ is volumetric water content $\left[L^{3} \cdot L^{-3}\right], t$ is time [T], $K(\psi)$ is saturated/unsaturated hydraulic conductivity $\left[L . T^{-1}\right], \psi$ is pressure head $[L], \mathrm{Z}$ represents the vertical coordinate $[L]$ whose positive direction is assumed to be upward, and $q_{s u b, e}$ is exchange rate between subsurface and surface flows $\left[L^{3} \cdot L^{-3} \cdot T^{-1}\right]$. Equation (1) is a highly nonlinear partial differential equation whose three dimensional form requires six boundary conditions and one initial condition.

In this research, the van Genuchten's water retention and saturated/unsaturated hydraulic conductivity functions are used as follows (van Genuchten 1980).

$$
\begin{aligned}
& \theta(\psi)= \begin{cases}\frac{\theta_{s}-\theta_{r}}{\left(1+|\alpha \psi|^{\mathbf{n}}\right)^{\mathbf{m}}}+\theta_{r}, & \psi<0 \\
\theta_{s}, & \psi \geq 0\end{cases} \\
& K=K_{S} \Theta^{l}\left[1-\left(1-\Theta^{\frac{1}{m}}\right)^{\mathbf{m}}\right]^{2}, \quad \mathbf{m}=1-\frac{1}{\mathbf{n}} \quad, \quad \mathbf{n}>1
\end{aligned}
$$

Where $\theta_{s}$ and $\theta_{r}$ are saturated and residual water contents respectively [-], $\alpha$ is air-entry-related parameter $\left[L^{-1}\right], \mathbf{m}$ and $\mathbf{n}$ are pore size distribution indices [-], $K_{S}$ is saturated hydraulic conductivity $\left[L . T^{-1}\right], l$ is pore connectivity parameter that was suggested to be 0.5 for an extensive range of soils. Finally, $\Theta$ is effective saturation [-], which can be defined as follows:

$\Theta=\frac{\theta-\theta_{r}}{\theta_{s}-\theta_{r}}$

\subsection{Surface flow}

In this study, two dimensional overland flow is described by the depth-averaged flow equations commonly referred to as Saint-Venant equations (e.g. Weill et al. 2009), consisting of one continuity and two momentum equations. The continuity equation is as follows:

$\frac{\partial h}{\partial t}+\vec{\nabla} \cdot(\vec{U} h)=q_{\text {sur }}+q_{\text {sur }, e}$

Where $h$ is the depth of surface flow representing pressure $[L], \vec{U}$ is depth-averaged velocity vector $\left[L . T^{-1}\right]$, $q_{\text {sur }}$ is source term representing rainfall $\left[L . T^{-1}\right], q_{s u r, e}$ is the flow rate exchanged with subsurface equation $\left[L . T^{-1}\right]$ (An and $\mathrm{Yu}$ 2014). Applying the diffusion wave approximation to the momentum equations, and combining them with the Manning-Strickler formula (Lal 1998; Weill et al. 2009; An and Yu 2014):

$U_{i}=-\left(\frac{h^{2 / 3}}{n_{\operatorname{man}} \sqrt{\mathbf{S}}}\right) \frac{\partial(h+z)}{\partial x_{i}}$

Where $U_{i}$ represents velocity along the $\mathrm{i}^{\text {th }}$ coordinate direction, namely $x_{i}, n_{\text {man }}$ is Manning's coefficient and $\mathbf{S}$ is known as mean local slope. Assuming that the water depth gradient is much smaller than the surface elevation gradient, the mean local slope equation can be written as follows (An and Yu 2014):

$\mathbf{S}=\sqrt{\left(\frac{\partial z}{\partial x}\right)^{2}+\left(\frac{\partial z}{\partial y}\right)^{2}}$

Combination of equations (5) and (6) results in a diffusion equation for surface flow (An and Yu 2014). 
$\frac{\partial h}{\partial \mathrm{t}}-\vec{\nabla} \cdot(\widetilde{K} \nabla(h+z))=q_{\text {sur }}+q_{\text {sur }, e}$

where

$\widetilde{K}=\frac{h^{5 / 3}}{n_{\operatorname{man}} \sqrt{\mathbf{S}}}$

\subsection{Discretization of the subsurface flow equation}

To apply the finite volume approach on the 3D mixed form of Richards' equation, with the assumption of constant $\theta$ and $q_{s u b, e}$ throughout the control volume, equation (1) is integrated over an arbitrary hexahedron control volume (Figure 1). In order to handle the second term of equation (1), assuming $\vec{F}=K \vec{\nabla}(\psi+z)$ and using the Green-Gauss divergence theorem simultaneously, yields:

$\iiint_{V o l} \nabla \cdot \vec{F} d V o l=\oiint_{S} \vec{F} \cdot d S \approx \vec{F}_{e} \cdot \vec{S}^{e}-\vec{F}_{w} \cdot \vec{S}^{w}+\vec{F}_{n} \cdot \vec{S}^{n}-\vec{F}_{S} \cdot \vec{S}^{s}+\vec{F}_{t o p} \cdot \vec{S}^{t o p}-\vec{F}_{b o t} \cdot \vec{S}^{b o t}$

Where $S^{B}$ represents contravariant vectors $\left[L^{2}\right]$ i.e. normal vectors to control volume surfaces whose magnitude is equal to the corresponding surface area. The superscript $B$ corresponds to $\{e, w, n, s, t o p, b o t\}$, where the letters in braces stand for the west, east, south, north, top and bottom side faces of the control volume. $\mathrm{Vol}$ represents the volume of the arbitrary hexahedron control volume $\left[L^{3}\right]$.

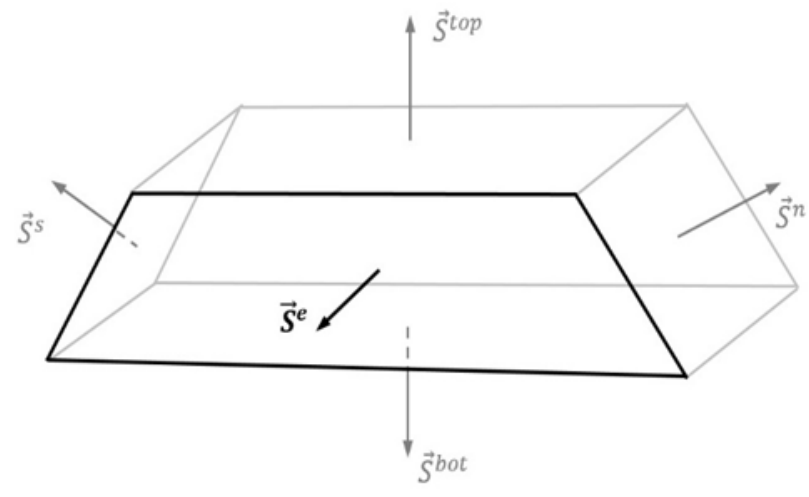

(a)

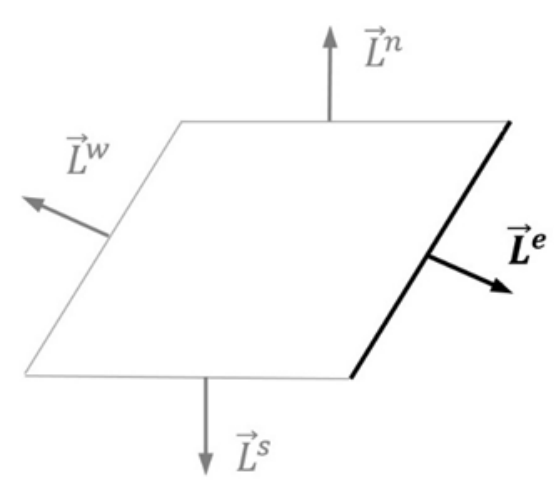

(b)

Fig. 1 Illustration of (a) 3D and (b) 2D general control volumes

Using the expansion of $\vec{F}$, Integration of Richards' equation in a Cartesian coordinate system yields,

$\operatorname{Vol}_{i, j, k} \frac{\partial \theta_{i, j, k}}{\partial t}-\left[\sum_{B} K_{B} \vec{\nabla}(\psi+z)_{B} \cdot \vec{S}^{B}\right]_{i, j, k}-\left(\operatorname{Vol} \cdot q_{s u b, e}\right)_{i, j, k}=0$

Where the subscripts $i, j$ and $k$ are grid point counters along the $\mathrm{x}, \mathrm{y}$ and $\mathrm{z}$ directions, respectively.

This study aims at simulating water flow in irregular cross sections and rugged topographies. Consequently, the orthogonal numerical grid is unlikely to be coincident with irregular-shaped boundaries. In order to improve model flexibility, one can transform the governing equations from the Cartesian coordinate system to a Curvilinear 
coordinate system using a Coordinate transformation method (Thompson et al. 1985). With this method, we map the governing equations expressed in the physical space $(x, y, z)$, a space that comprises real-world solution domain and may include non-orthogonal grids, onto a computationally ideal domain with orthogonal grids and unit mesh sizes, known as the computational space $(\xi, \eta, \zeta)$ (An and Yu 2014).

Applying coordinate transformation to $(\psi+z)$ gradients at the control volume surfaces of equation (10) gives,

$\operatorname{Vol}_{i, j, k} \frac{\partial \theta_{i, j, k}}{\partial t}-\left[\sum_{B} K_{B}\left(\sum_{b=1}^{3} \operatorname{Coef}_{\xi_{b}} \frac{\partial(\psi+z)}{\partial \xi_{\mathrm{b}}}\right)_{B}\right]_{i, j, k}-\left(\text { Vol. } q_{s u b, e}\right)_{i, j, k}=0$

Where $\operatorname{Coef}_{\xi_{\boldsymbol{b}}}$ includes geometric constants of the transformation expressed as follows,

$\left.\operatorname{Coef}_{\xi_{b}}\right|_{b=1,2,3}=\sum_{\beta=1}^{3} \frac{\partial \xi_{b}}{\partial x_{\beta}} \cdot S_{x_{\beta}} \quad,\left\{\xi_{1}, \xi_{2}, \xi_{3}\right\}=\{\xi, \eta, \zeta\}$ and $\left\{x_{1}, x_{2}, x_{3}\right\}=\{x, y, z\}$

In this equation, $S_{x_{\beta}}$ represents the components of the contravariant vectors along the $x, y$ and $z$ directions. The $\partial \xi_{b} / \partial x_{\beta}$ derivatives, known as transformation metrics, are defined as follows,

$\xi_{x}=\frac{\left(y_{\eta} z_{\zeta}-y_{\zeta} z_{\eta}\right)}{J_{\text {sub }}} \quad, \quad \xi_{y}=\frac{\left(z_{\eta} x_{\zeta}-z_{\zeta} x_{\eta}\right)}{J_{\text {sub }}} \quad, \quad \xi_{z}=\frac{\left(x_{\eta} y_{\zeta}-x_{\zeta} y_{\eta}\right)}{J_{\text {sub }}}$

$\eta_{x}=\frac{\left(y_{\zeta} z_{\xi}-y_{\xi} z_{\zeta}\right)}{J_{\text {sub }}} \quad, \quad \eta_{y}=\frac{\left(z_{\zeta} x_{\xi}-z_{\xi} x_{\zeta}\right)}{J_{\text {sub }}} \quad, \quad \eta_{z}=\frac{\left(x_{\zeta} y_{\xi}-x_{\xi} y_{\zeta}\right)}{J_{\text {sub }}}$

$\zeta_{x}=\frac{\left(y_{\xi} z_{\eta}-y_{\eta} z_{\xi}\right)}{J_{\text {sub }}} \quad, \quad \zeta_{y}=\frac{\left(z_{\xi} x_{\eta}-z_{\eta} x_{\xi}\right)}{J_{\text {sub }}} \quad, \quad \zeta_{z}=\frac{\left(x_{\xi} y_{\eta}-x_{\eta} y_{\xi}\right)}{J_{\text {sub }}}$

Where $J_{\text {sub }}$ is the Jacobian of transformation, which is defined as,

$J_{\text {sub }}=x_{\xi}\left(y_{\eta} z_{\zeta}-y_{\zeta} z_{\eta}\right)+x_{\eta}\left(y_{\zeta} z_{\xi}-y_{\xi} z_{\zeta}\right)+x_{\zeta}\left(y_{\xi} z_{\eta}-y_{\eta} z_{\xi}\right)$

The symbol $x_{\beta_{\xi_{b}}}$ for $\beta=b=\{1,2,3\}$ stands for derivative of $x_{\beta}$ with respect to $\xi_{b}$. Its values can be estimated by a finite difference approach as shown below for $x_{\xi_{b}}$ for $b=\{1,2,3\}$ at the eastern face of the control volume:

$\left.\frac{\partial x}{\partial \xi}\right|_{i+\frac{1}{2}, j, k}=\frac{x_{i+1, j, k}-x_{i, j, k}}{\Delta \xi}$

$\left.\frac{\partial x}{\partial \eta}\right|_{i+\frac{1}{2}, j, k}=\frac{1}{2}\left(\frac{x_{i+1, j+1, k}-x_{i+1, j-1, k}}{2 \Delta \eta}+\frac{x_{i, j+1, k}-x_{i, j-1, k}}{2 \Delta \eta}\right)$

$\left.\frac{\partial x}{\partial \zeta}\right|_{i+\frac{1}{2}, j, k}=\frac{1}{2}\left(\frac{x_{i+1, j, k+1}-x_{i+1, j, k-1}}{2 \Delta \zeta}+\frac{x_{i, j, k+1}-x_{i, j, k-1}}{2 \Delta \zeta}\right)$

The transformed gradients of $(\psi+z)$ on each control volume boundary are calculated using the same procedure applied in equation (16) to the eastern face: 
$\left.\frac{\partial(\psi+z)}{\partial \xi}\right|_{i+\frac{1}{2}, j, k}=\frac{(\psi+z)_{i+1, j, k}-(\psi+z)_{i, j, k}}{\Delta \xi}$

$\left.\frac{\partial(\psi+z)}{\partial \eta}\right|_{i+\frac{1}{2}, j, k}=\frac{1}{2}\left(\frac{(\psi+z)_{i+1, j+1, k}-(\psi+z)_{i+1, j-1, k}}{2 \Delta \eta}+\frac{(\psi+z)_{i, j+1, k}-(\psi+z)_{i, j-1, k}}{2 \Delta \eta}\right)$

$\left.\frac{\partial(\psi+z)}{\partial \zeta}\right|_{i+\frac{1}{2}, j, k}=\frac{1}{2}\left(\frac{(\psi+z)_{i+1, j, k+1}-(\psi+z)_{i+1, j, k-1}}{2 \Delta \zeta}+\frac{(\psi+z)_{i, j, k+1}-(\psi+z)_{i, j, k-1}}{2 \Delta \zeta}\right)$

Unsaturated hydraulic conductivity was estimated at control volume faces as the arithmetic average of hydraulic conductivity at the two neighboring grids. Equation (18) presents an example of unsaturated hydraulic conductivity estimation at the eastern face of a control volume:

$K_{i+\frac{1}{2}, j, k}=\frac{\left(K_{i, j, k}+K_{i+1, j, k}\right)}{2}$

The use of geometric and harmonic averages is also possible, but this might lead to underestimation of the hydraulic conductivity at the wetting front (Van Dam and Feddes 2000).

\subsection{Linearization of the subsurface equation with an underrelaxed-modified Picard scheme}

The highly non-linear equation of saturated/unsaturated subsurface flow requires linearization during the numerical solution process. In this research, Picard iteration was used for this purpose, owing to its simplicity, cost-efficiency on an individual iteration basis, and linear convergence rate (An et al. 2012). Temporal discretization of the 3D Richards' equation was performed using the well-known numerical procedure introduced by Celia et al. (1990), based on Taylor series expansion of the storage term, discretized with a backward Euler method.

$\frac{\theta_{i, j, k}^{n+1, m+1}-\theta_{i, j, k}^{n}}{\Delta t}=\frac{\theta_{i, j, k}^{n+1, m}-\theta_{i, j, k}^{n}}{\Delta t}+\frac{C_{w_{i, j, k}^{n+1, m}}^{n+} \cdot\left(\psi_{i, j, k}^{n+1, m+1}-\psi_{i, j, k}^{n+1, m}\right)}{\Delta t}$

Where $n$ represents the number of time steps and $m$ represents the number of iterations. At convergence, $\theta_{i, j, k}^{n+1, m+1}=\theta_{i, j, k}^{n+1, m}$ and $\psi_{i, j, k}^{n+1, m+1}=\psi_{i, j, k}^{n+1, m}$. Consequently, the method is independent of the water capacity function, which is the origin of mass balance error (Kosugi 2008). To increase convergence rate and avoid oscillatory solutions, the implementation of a relaxation technique is suggested (Paniconi and Putti 1994; Durbin and Delemos 2007).

$\psi_{i, j, k}^{n+1, m+1}=\psi_{i, j, k}^{n+1, m}+\varphi\left(\psi_{i, j, k}^{n+1, m+1}-\psi_{i, j, k}^{n+1, m}\right)$

Where $\varphi$ is underrelaxation factor. Celia et al. (1990) named their Taylor series-based model for Richards' equation as Modified Picard Iteration method. With the use of an underrelaxation factor, which is expected to have a positive effect on the convergence of the coupled surface-subsurface model, the proposed method is referred to as Underrelaxed-Modified Picard Iteration.

\subsection{Discretization of the surface flow equations}

The 2D Saint-Venant equation, Equation (8), was discretized in the same manner as the subsurface equation. In this case, the governing equations were integrated over a quadrangular-shaped control volume (Figure 1). Assuming $\overrightarrow{\widetilde{F}}=\widetilde{K} \vec{\nabla}(h+z)$ and using the Gauss-Green divergence theorem, the second term of equation (8) could be written as, 
$\iint_{A} \nabla \cdot \vec{F} d A=\oint_{L} \overrightarrow{\widetilde{F}} \cdot d L \approx \overrightarrow{\widetilde{F}}_{e} \cdot \vec{L}^{e}-\overrightarrow{\widetilde{F}}_{w} \cdot \vec{L}^{w}+\overrightarrow{\widetilde{F}}_{n} \cdot \vec{L}^{n}-\overrightarrow{\widetilde{F}}_{s} \cdot \vec{L}^{s}$

Where $\vec{L}^{G}$ is the contravariant vector $[L]$ i.e. normal vector to the 2D control volume sides whose magnitude is equal to the corresponding surface length. Superscript $G$ is $\{e, w, n, s\}$, in which the letters in the braces stand for east, west, north and south sides of the 2D control volume, respectively. $A$ represents the surface of a 2D control volume. Hence, integrating the diffusion form of Saint-Venant equation in Cartesian coordinate system yields,

$A_{i, j} \frac{\partial h_{i, j}}{\partial t}-\left[\sum_{G} \widetilde{K_{G}} \nabla(h+z)_{G} \cdot \vec{L}_{G}\right]_{i, j}-A_{i, j}\left(q_{\text {sur }}+q_{s u r, e}\right)_{i, j}=0$

Where subscripts $i, j$ are grid point counters along the $x$ and $y$ directions, respectively.

Using the coordinate transformation approach, equation (21) is transformed from a Cartesian coordinate system to a Curvilinear coordinate system,

$A_{i, j} \frac{\partial h_{i, j}}{\partial t}-\left[\sum_{G} \widetilde{K_{G}}\left(\operatorname{Coef}_{\xi_{g}} \frac{\partial(h+z)}{\partial \xi_{g}}\right)_{G}\right]_{i, j}-A_{i, j}\left(q_{s u r}+q_{s u r, e}\right)_{i, j}=0$

Where $\operatorname{Coef}_{\xi_{g}}$ includes geometric constants of the transformation expressed as follows,

$\left.\operatorname{Coef}_{\xi_{g}}\right|_{g=1,2}=\sum_{\Omega=1}^{2} \frac{\partial \xi_{g}}{\partial x_{\Omega}} \cdot L_{x_{\Omega}} \quad,\left\{\xi_{1}, \xi_{2}\right\}=\{\xi, \eta\}$ and $\left\{x_{1}, x_{2}\right\}=\{x, y\}$

Where, $L_{x_{\Omega}}$ represents the components of contravariant vectors of 2D control volumes and the transformation metrics, $\xi_{g} / \partial x_{\Omega}$, which are defined as follows,

$\xi_{x}=\frac{y_{\eta}}{J_{\text {sur }}} \quad, \quad \xi_{y}=-\frac{x_{\eta}}{J_{\text {sur }}}$

$\eta_{x}=-\frac{y_{\xi}}{J_{\text {sur }}} \quad, \quad \eta_{y}=\frac{x_{\xi}}{J_{\text {sur }}}$

The Jacobian of transformation for 2D equation, $J_{\text {sur }}$, is defined as,

$J_{\text {sur }}=x_{\xi} y_{\eta}-x_{\eta} y_{\xi}$

Where the derivatives $x_{\Omega_{\xi}}$ for $\Omega=g=\{1,2\}$ can be estimated in a similar manner as equation (16), whose discretized form of $x_{\xi_{g}}$ for $g=\{1,2\}$ at the eastern face of the control volume is as follows,

$\left.\frac{\partial x}{\partial \xi}\right|_{i+\frac{1}{2}, j}=\frac{x_{i+1, j}-x_{i, j}}{\Delta \xi}$
$\left.\frac{\partial x}{\partial \eta}\right|_{i+\frac{1}{2}, j}=\frac{1}{2}\left(\frac{x_{i+1, j+1}-x_{i+1, j-1}}{2 \Delta \eta}+\frac{x_{i, j+1}-x_{i, j-1}}{2 \Delta \eta}\right)$

The transformed gradients of $(h+z)$ on the borders of the control volume were estimated as follows, 
$\left.\frac{\partial(h+z)}{\partial \xi}\right|_{i+\frac{1}{2}, j}=\frac{(h+z)_{i+1, j}-(h+z)_{i, j}}{\Delta \xi}$
$\left.\frac{\partial(h+z)}{\partial \eta}\right|_{i+\frac{1}{2}, j}=\frac{1}{2}\left[\frac{(h+z)_{i+1, j+1}-(h+z)_{i+1, j-1}}{2 \Delta \eta}+\frac{(h+z)_{i, j+1}-(h+z)_{i, j-1}}{2 \Delta \eta}\right]$

Parameter $\widetilde{K}$ in equation (9) was estimated by an Upwind technique, whose value at the eastern boundary can be calculated as,

$\widetilde{K}_{e_{i, j}}= \begin{cases}\widetilde{K}_{i+1, j} & ,(h+z)_{i, j} \leq(h+z)_{i+1, j} \\ \widetilde{K}_{i, j} & , \quad(h+z)_{i+1, j}<(h+z)_{i, j}\end{cases}$

\subsection{Linearization of surface equation with an underrelaxed Picard scheme}

The temporal term of the 2D Saint-Venant equation was discretized using the backward Euler method:

$\frac{\partial h_{i, j}}{\partial t}=\frac{h_{i, j}^{n+1}-h_{i, j}^{n}}{\Delta t}$

Following the procedure applied to the Richards' equation, the overland flow equation was linearized through an underrelaxed Picard scheme.

$h_{i, j}^{n+1, m+1}=\max \left\{h_{i, j}^{n+1, m}+\varphi\left(h_{i, j}^{n+1, m+1}-h_{i, j}^{n+1, m}\right), \quad 0.0\right\}$

Where the maximum operator was applied to equation (31) in order to prevent negative head values affecting surface water volume (An and Yu 2014).

\subsection{Coupling surface and subsurface flow equations}

Enforcing continuity of pressure in the surface-subsurface interface, the governing equations were coupled and the exchanged flux between both domains was estimated as follows (Figure 2):

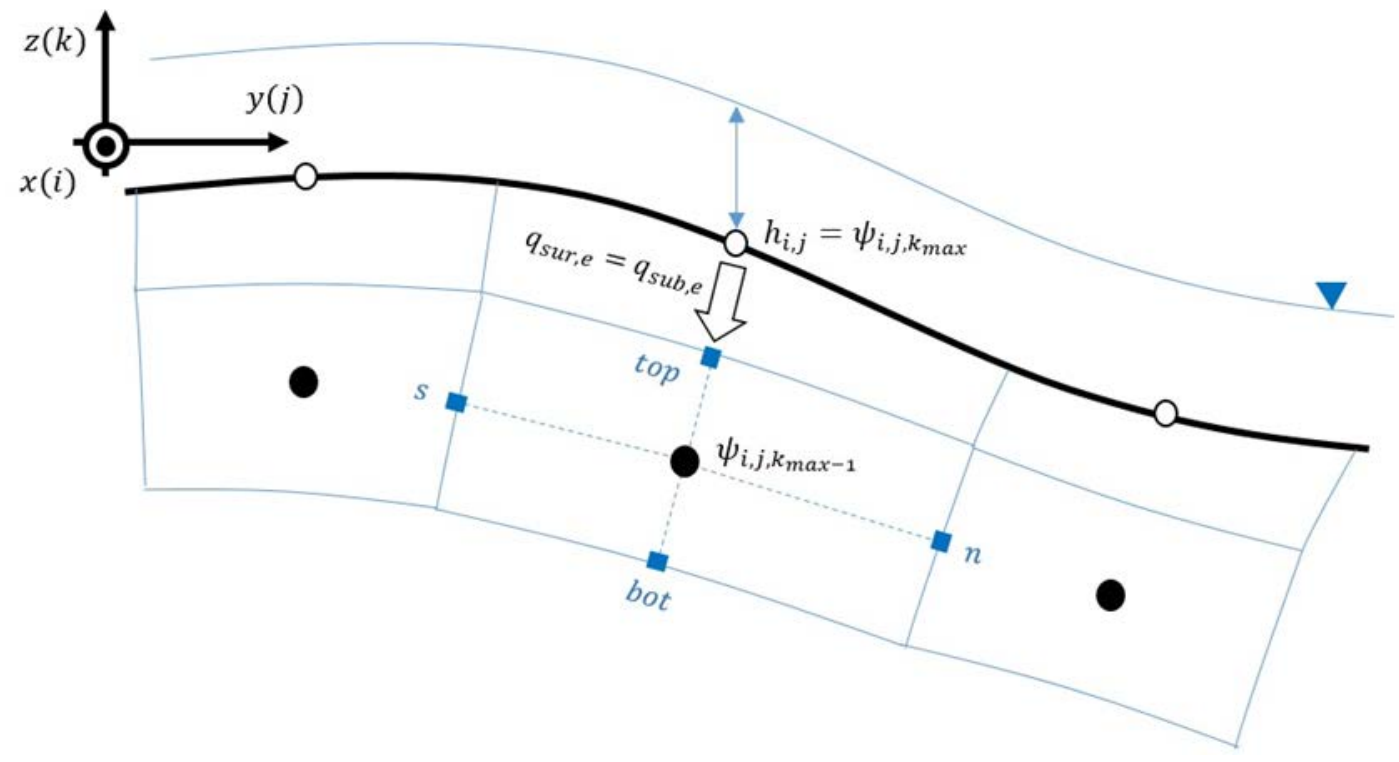

Fig. 2 Coupling surface and subsurface flow equations by enforcing continuity of pressure in the surface and subsurface interface 
$\left(\text { Vol. } q_{s u b, e}\right)_{i, j, k_{\max }}=-\left(S . q_{s u r, e}\right)_{i, j}=\left\{[K \vec{\nabla}(\psi+z) \cdot \vec{S}]_{t o p}\right\}_{i, j, k_{\max }-1}$

Where the right-hand equation is the Buckingham-Darcy equation, applied to the top interface of the control volume lying beneath the surface-subsurface interface. The water abstracted from overland flow enters the subsurface domain as boundary condition on the nodes lying at the top of the subsurface domain, which is coincident with surface flow cells. The $(\psi+z)$ gradients on the top interface of the control volumes lying below the surface $\left(i, j, k_{\max }-1\right)$ were discretized as follows:

$$
\begin{aligned}
& \left.\frac{\partial(\psi+z)}{\partial \xi}\right|_{i, j, k_{\max }-\frac{1}{2}}=\frac{1}{2}\left(\frac{(\psi+z)_{i+1, j, k_{\max }-1}-(\psi+z)_{i-1, j, k_{\max }-1}}{2 \Delta \xi}+\frac{(h+z)_{i+1, j}-(h+z)_{i-1, j}}{2 \Delta \xi}\right) \\
& \left.\frac{\partial(\psi+z)}{\partial \eta}\right|_{i, j, k_{\max }-\frac{1}{2}}=\frac{1}{2}\left(\frac{(\psi+z)_{i, j+1, k_{\max }-1}-(\psi+z)_{i, j-1, k_{\max }-1}}{2 \Delta \eta}+\frac{(h+z)_{i, j+1}-(h+z)_{i, j-1}}{2 \Delta \eta}\right) \\
& \left.\frac{\partial(\psi+z)}{\partial \zeta}\right|_{i, j, k_{\max }-\frac{1}{2}}=\frac{(h+z)_{i, j}-(\psi+z)_{i, j, k_{\max }-1}}{\Delta \zeta}
\end{aligned}
$$

\subsection{Dynamic time step, linear system solver and convergence criterion}

The linearized system of equations was solved using an Alternating Direction Implicit (ADI) method, which is well-known for its simplicity and cost efficiency (An et al. 2011). This method was first introduced by Peaceman and Rachford (Peaceman and Rachford 1955), and has been applied to water flow simulation (Perrens and Watson 1977; Weeks et al. 2004). In order to improve the model computational speed, we used a dynamic time stepping approach, first introduced by Paniconi and Putti (1994).

The convergence criterion introduced by Huang et al. (1996) was applied to the subsurface equation.

$$
C_{w}^{n+1, m}\left|\psi^{n+1, m+1}-\psi^{n+1, m}\right|=\left|\theta^{n+1, m+1}-\theta^{n+1, m}\right| \leq \delta_{\theta}
$$

Where $\delta_{\theta}$ is the convergence tolerance for the subsurface equation, whose value in this research lied between $10^{-4}$ and $10^{-5}$. This criterion was proposed for the mixed form algorithm of Celia et al. (1990). The criterion has been proved capable of optimizing the number of iterations needed to achieve a convergent solution. The effectiveness of this criterion has been highlighted for the simulation of water flow in coarse-textured soils (Huang et al. 1996).

The convergence criterion for the surface equation was set as:

$\left|h^{n+1, m+1}-h^{n+1, m}\right| \leq \delta_{h}$

Where $\delta_{h}$ is the convergence tolerance of the surface equation. In this paper, the values of $\delta_{h}$ ranged between $10^{-4}$ and $10^{-5} \mathrm{~m}$.

The Curvilinear Coupled Surface-Subsurface model (CCSS) described above was developed as a FORTRAN code. Model capacities were tested through a number of test cases. 


\subsection{Analysis of Mass Balance Error (MBE) and CPU Time}

The time evolution of mass balance error was calculated for the first three validation cases using equation (36), as introduced by Celia et al. (1990).

$M B E(t)=\left|1-\frac{\text { Total additional mass in the domain }}{\text { Total net flux into the domain }}\right|$

Where the total additional mass was measured with respect to the initial mass in the system. The total net flux into the domain is the flux balance integrated with respect to time up to the current time step. CPU time was also measured for the first three validation cases. An Intel ${ }^{\circledR}$ processor with a speed of $2.4 \mathrm{GHz}$ was used for all simulation runs.

\section{Results and Discussion}

In this section, the proposed model is validated with results obtained from published models, analytical solutions and irrigation experiments. Validation was first applied to the subsurface and surface models. After validation, the model was applied to the simulation of irrigation in a highly-undulated basin.

Table 1 presents the parameters of the van Genuchten's model for water retention and unsaturated hydraulic conductivity functions corresponding to the soils used in this research.

Table 1- Constant parameters of van Genuchten's model

\begin{tabular}{ccccccc}
\hline $\begin{array}{c}\text { Soil } \\
\text { No. }\end{array}$ & Texture & $\theta_{S}(-)$ & $\theta_{r}(-)$ & $n(-)$ & $\alpha\left(\frac{1}{c m}\right)$ & $\boldsymbol{K}\left(\frac{\boldsymbol{c m}}{\boldsymbol{d a y}}\right)$ \\
\hline 1 & Clay $^{\mathrm{a}}$ & 0.380 & 0.068 & 1.09 & 0.008 & 4.80 \\
2 & Loam $^{\mathrm{a}}$ & 0.430 & 0.078 & 1.56 & 0.036 & 24.96 \\
3 & Sand $^{\mathrm{a}}$ & 0.430 & 0.045 & 2.68 & 0.145 & 712.80 \\
4 & Sand $^{\mathrm{b}}$ & 0.314 & 0.041 & 1.63 & 0.053 & 14.40 \\
\hline
\end{tabular}

${ }^{a}$ soils used in section 3.1, obtained from the ROSETTA model (Schaap et al. 2001).

${ }^{\text {b }}$ Yuma Mesa soil used in section 3.3, obtained from Zerihun et al. (2005a).

\subsection{Validation: one dimensional infiltration in homogenous soil}

The subsurface model was verified through the simulation of a simple one dimensional infiltration process in three homogenous soils with clay, loam and sand textures (soils 1 to 3 in Table 1). The size of the soil blocks was $0.2 \mathrm{~m} \times 0.2 \mathrm{~m} \times 1 \mathrm{~m}$. The boundary condition at the top was set as Dirichlet type $\left(\psi_{i, j, k_{\max }}=-0.2 \mathrm{~m}\right)$. The boundary condition at the bottom was free drainage $\left(\nabla_{n}(\psi)=0\right)$. Vertical boundaries were set as no-flow, and the initial condition was $\psi=-10 \mathrm{~m}$ throughout the domain.

The mesh size independency of the subsurface model was tested in the sand soil. The mesh size was refined along the $\mathrm{Z}$ direction to achieve a mesh independent solution. Five grids $(9 \times 9 \times 21,9 \times 9 \times 41,9 \times 9 \times 81,9 \times$ $9 \times 161$, and $9 \times 9 \times 321$ ) were simulated for both orthogonal and non-orthogonal grids. Figure 3 presents a scheme of the orthogonal and non-orthogonal grids involved in the one dimensional infiltration test. Figure 4 presents the convergence behavior of solutions with mesh size refinement. The total simulated time was $12 \mathrm{~h}$. 


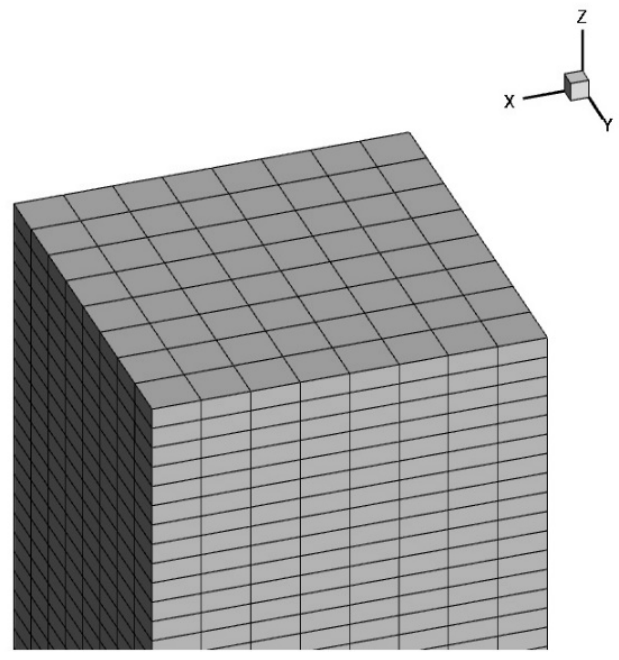

(a)

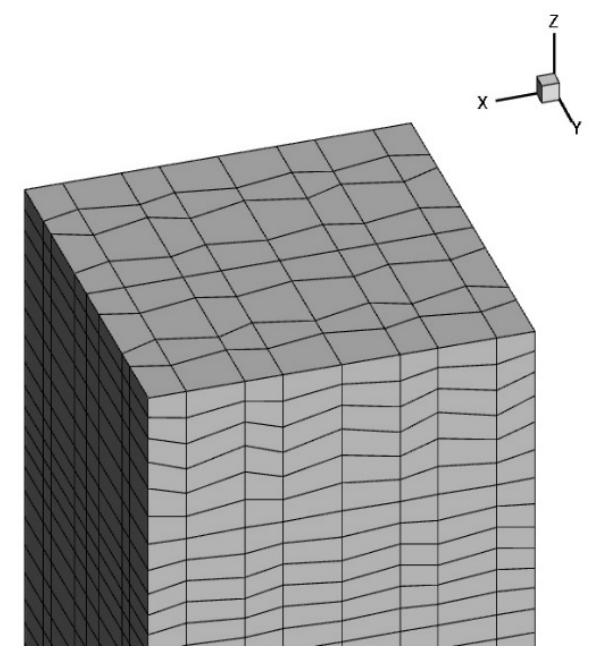

(b)

Fig. 3 (a) Orthogonal and (b) non-orthogonal grids used for simulation of one dimensional infiltration in clay, loam and sand soil textures

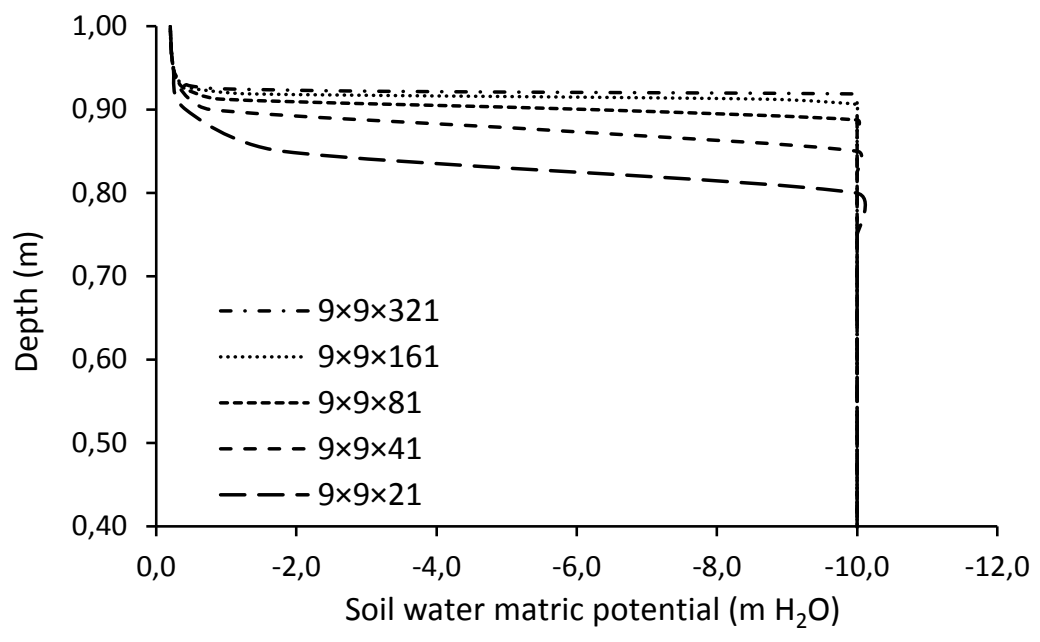

(a)

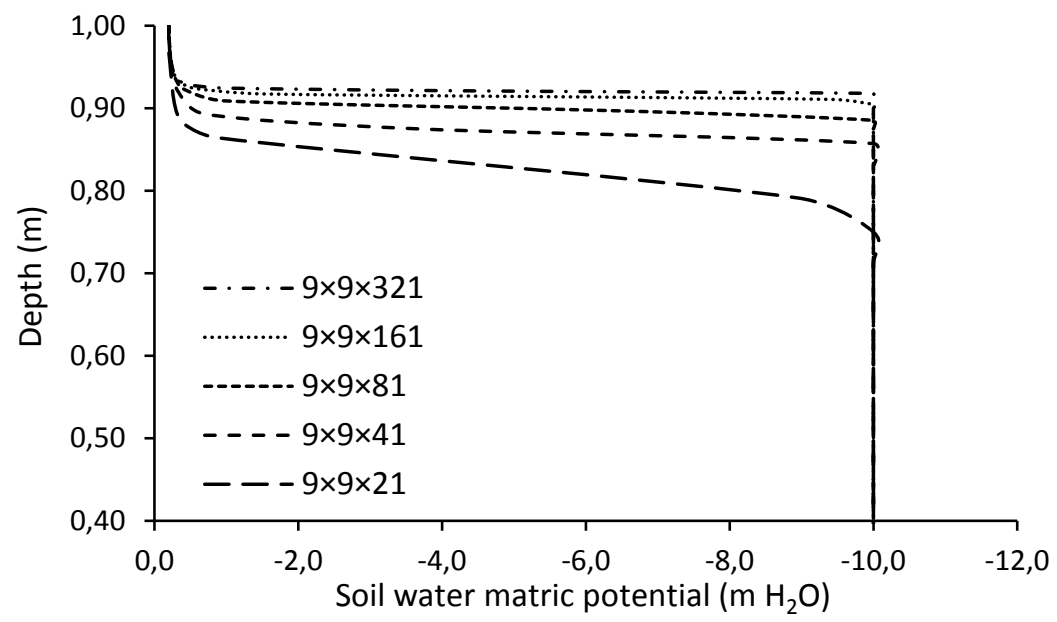

(b)

Fig. 4 Convergence behavior of solutions for the one dimensional infiltration test using (a) orthogonal (b) non-orthogonal grids 
Mesh refinement leads to convergence in the solutions, with grids $9 \times 9 \times 161$ and $9 \times 9 \times 321$ yielding very similar solutions. The results of the $9 \times 9 \times 161$ grid were validated with the results of the HYDRUS-1D software (Šimůnek et al. 2013). Figure 5 compares the solutions of the one dimensional infiltration test obtained from CCSS and HYDRUS-1D.

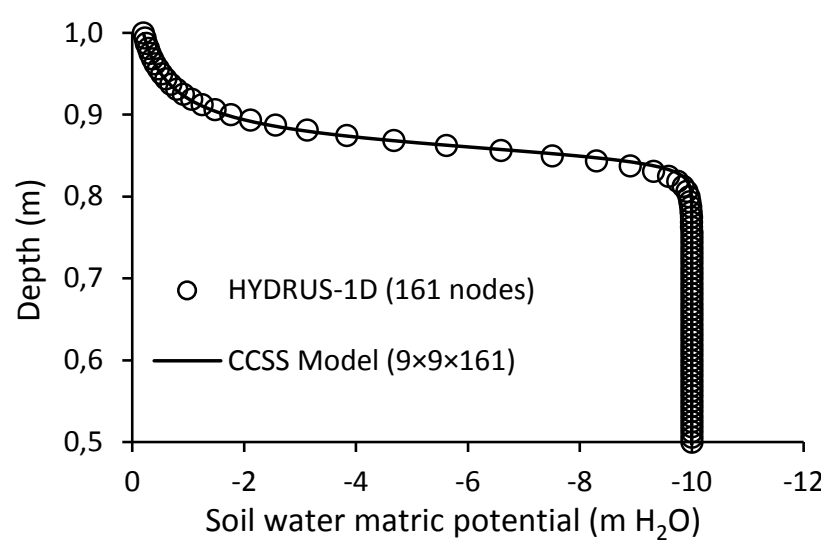

(a)

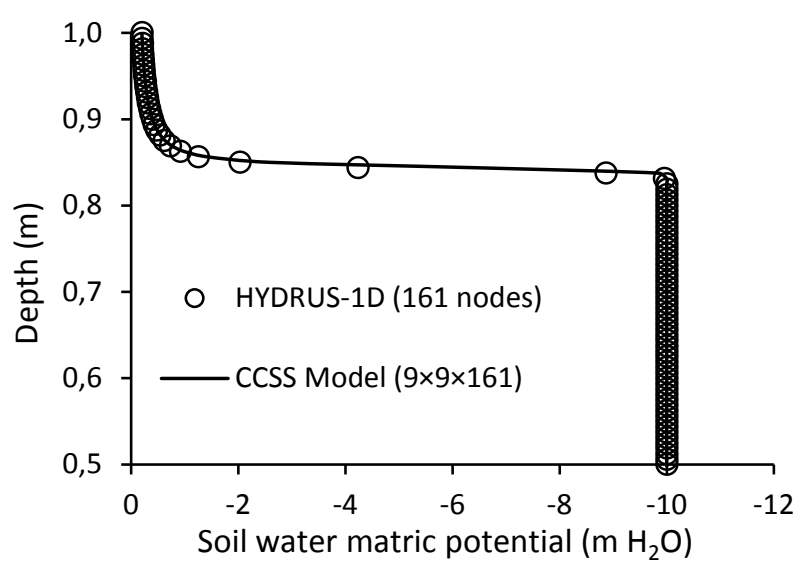

(c)

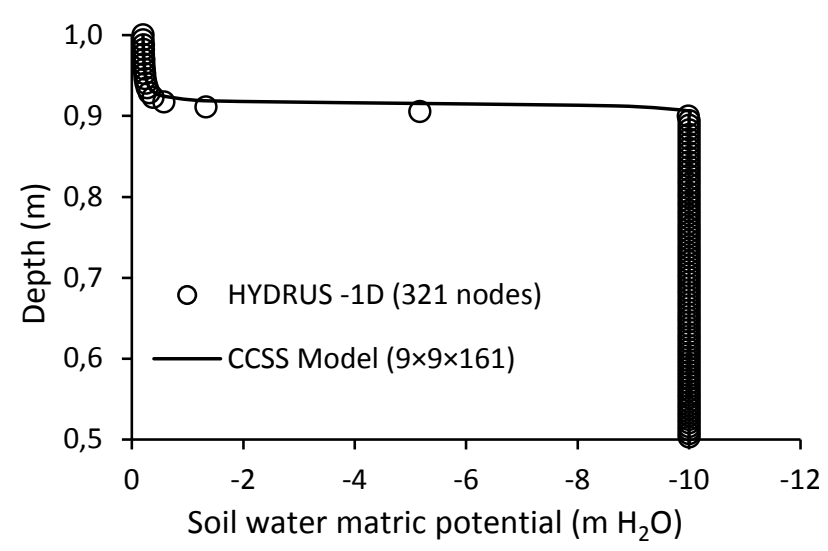

(e)

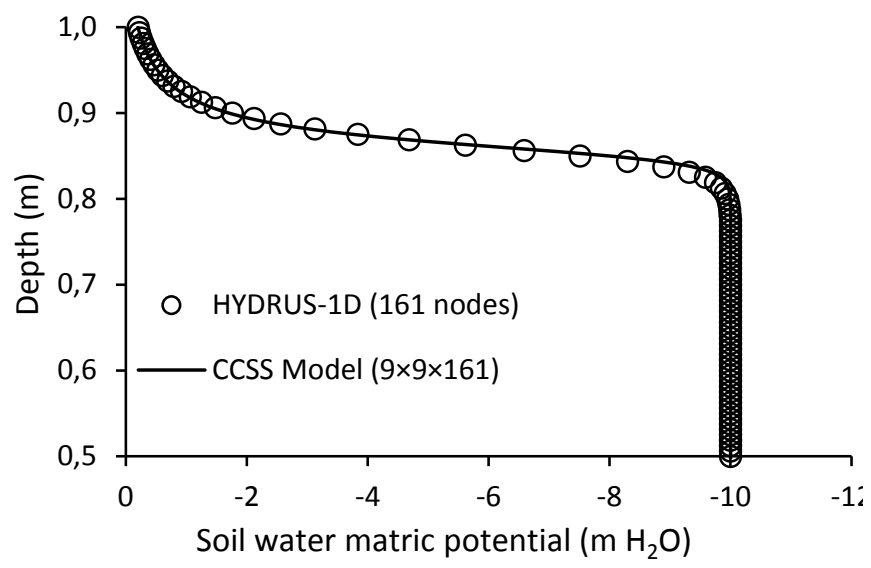

(b)

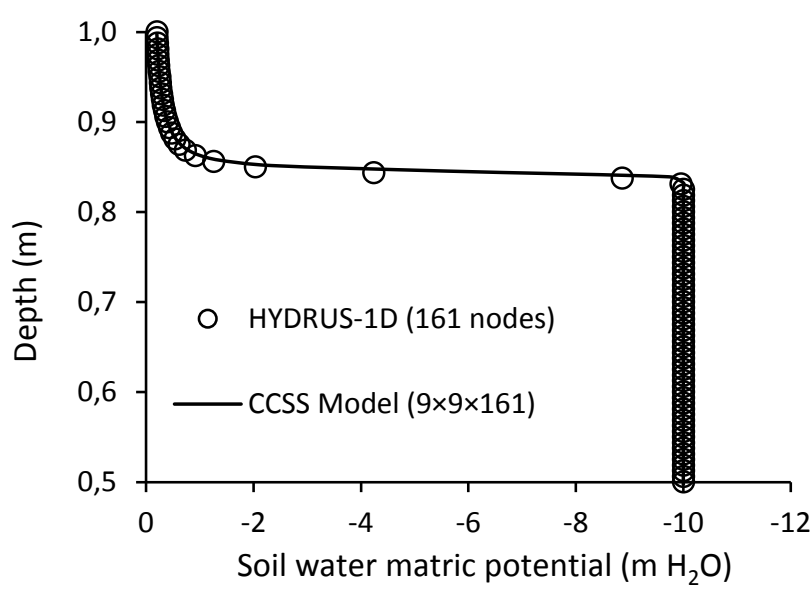

(d)

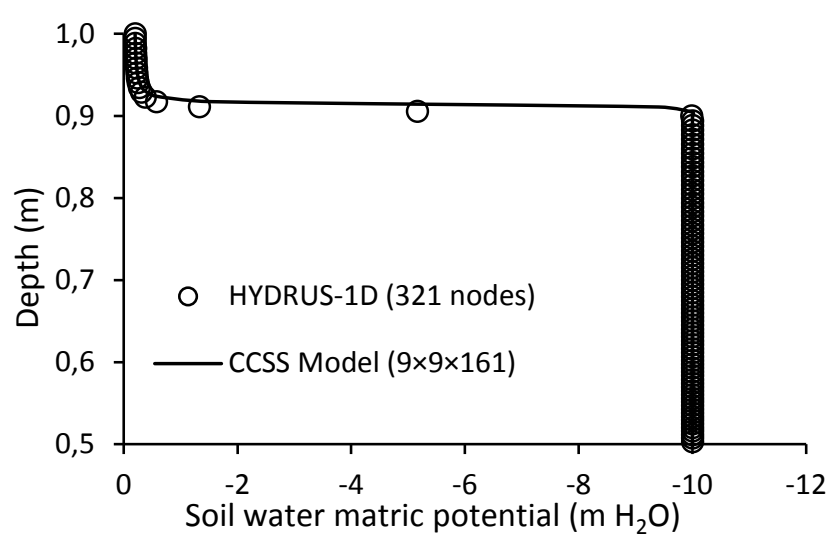

(f)

Fig. 5 Comparison of CCSS model and HYDRUS-1D simulations for Clay ( $a$ and b), Loam (c and d) and Sand (e and f) soils. (a), (c) and (e) implemented orthogonal grids, whereas (b), (d) and (f) implemented nonorthogonal grids

The results of CCSS and HYDRUS-1D showed excellent agreement in a wide range of soil texture. Figure 6 shows the time evolution of mass balance error for three soil textures with non-orthogonal grids $(9 \times 9 \times 161)$ in order to evaluate the subsurface code of CCSS model separately. 


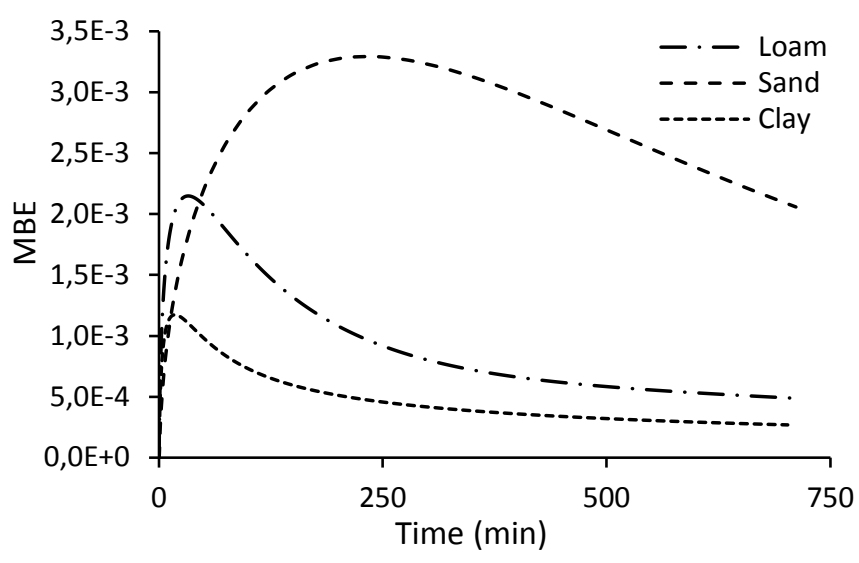

Fig. 6 Time evolution of mass balance error for non-orthogonal grids $(9 \times 9 \times 161)$ in section 3.1 for evaluation of subsurface code of CCSS model

In all soil textures the mass balance error increases in time, reaches a peak value and then decreases to approach a steady value of $10^{-3}-10^{-4}$. The same trend was observed for the orthogonal grids (results not presented), but the final mass balance error was $10^{-7}-10^{-8}$ for the three soil textures.

Table 2 shows the CPU time for all test cases in this section, including grids differing in density and orthogonality.

Table 2- CPU times calculated for one dimensional infiltration in homogenous soil (seconds).

\begin{tabular}{|c|c|c|c|c|c|c|}
\hline \multirow{2}{*}{ Grid } & \multicolumn{3}{|c|}{ Orthogonal } & \multicolumn{3}{|c|}{ Non-orthogonal } \\
\hline & Clay & Loam & Sand & Clay & Loam & Sand \\
\hline $9 \times 9 \times 21$ & 1.391 & 1.922 & 1.906 & 1.453 & 2.062 & 10.375 \\
\hline $9 \times 9 \times 41$ & 3.531 & 5.000 & 2.672 & 3.625 & 6.375 & 25.406 \\
\hline $9 \times 9 \times 81$ & 10.625 & 16.906 & 7.188 & 11.031 & 20.703 & 77.984 \\
\hline $9 \times 9 \times 161$ & 31.312 & 51.641 & 16.609 & 35.938 & 64.516 & 187.766 \\
\hline
\end{tabular}

CPU time generally increases with an increase in grid complexity, either in terms of mesh density or irregularity. More nodal values need to be calculated with increasing mesh density. Therefore, the number of iterative sweeps increases, and so does the CPU time. Results in Table 2 indicate that the increase in CPU time with the number of nodes is quite linear in the explored range of grid size. Six potential regressions of CPU time vs. number of nodes on the results of Table 2 produced an average exponent of 1.50. Further, for instance for the sandy soil, nodal CPU time grew from $0.47 \times 10^{-3} \mathrm{~s} \mathrm{node}^{-1}$ to $1.39 \times 10^{-3} \mathrm{~s}$ node $\mathrm{e}^{-1}$ and then to $1.45 \times 10^{-3} \mathrm{~s}$ node $^{-1}$ in the three linear segments connecting the four experimental grids. The similitude of the two latter slopes and the low value of the potential exponent indicate that the simulation model can attain high computational efficiency when handling large grids.

The grid non-orthogonality shows the degree of dominance of cross-derivative terms. When orthogonal grids are used, only the normal-derivative terms undertake a change in each time step, and the cross-derivative terms equal zero. Therefore, the non-orthogonal grids require cross-derivative terms to be determined and used to update the solution. Hence, non-orthogonal grids increase the required CPU time. Table 2 also evidences the dependence of CPU time on soil type in this test case. The increase in CPU time with the use of non-orthogonal grids is also affected by soil type. Averaging the four experimental grids, the sandy soil requires much more CPU time (828\% more) when the grid changes from orthogonal to non-orthogonal. An increase in CPU time can also observed for clay and loam soil textures, but the magnitude is much smaller (6 and 21\%, respectively). This fact could be explained through the shape of the water retention curve of each soil type, and needs further investigations. 


\subsection{Validation: Analytical solution of one dimensional rainfall-runoff in an impervious channel}

Gottardi and Venutelli (1993) proposed an analytical solution for the diffusion form of one dimensional rainfall-runoff problem occurring in an impermeable channel. The input parameters are the same as reported by $\mathrm{He}$ et al. (2008), who simulated the outflow occurred out of a constant rainfall with a rate of $0.33 \frac{\mathrm{mm}}{\mathrm{min}}$ and duration of $200 \mathrm{~min}$ on a $400 \mathrm{~m}$ long channel. The bed slope was $0.0005 \frac{\mathrm{m}}{\mathrm{m}}$, with Manning roughness coefficient of $0.02 \mathrm{~s} . \mathrm{m}^{-1 / 3}$. The total simulation time was $300 \mathrm{~min}$. The boundary condition was set as zero depth gradient at the outlet, and no-flow at the other three boundaries. The initial condition was $h(x, y, 0)=0$. Similar to section 3.1, simulation was performed in orthogonal and non-orthogonal grids (Figure 7-b, c). The convergence of simulations is presented in Figure 8. Mesh sizes were refined along the surface flow direction to obtain $10 \times 25$, $10 \times 100,10 \times 200$ and $10 \times 400$ grids. As grids were refined, all simulations (orthogonal and non-orthogonal) converged to a unique hydrograph.

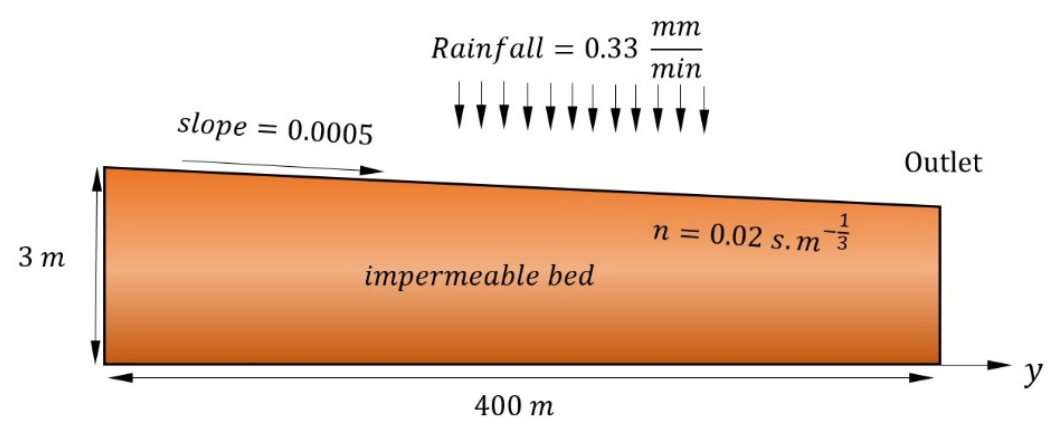

(a)

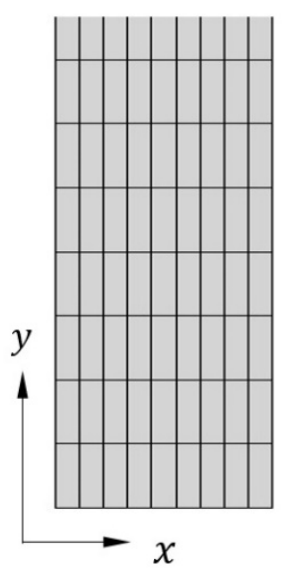

(b)

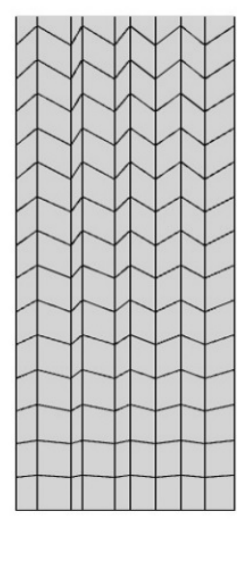

(c)

Fig. 7 Analytical solution of one dimensional rainfall-runoff in a channel. (a) Structure and flow domain of the one dimensional rainfall-runoff test case; (b) Orthogonal and (c) non-orthogonal grids used for simulation process

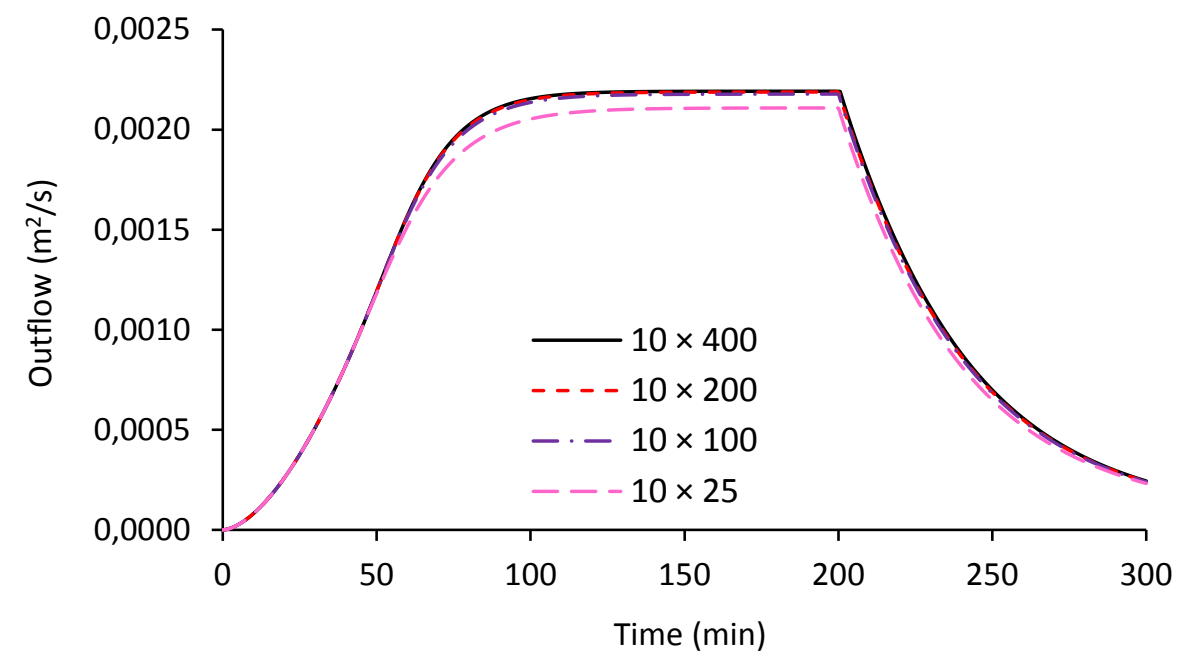

(a) 


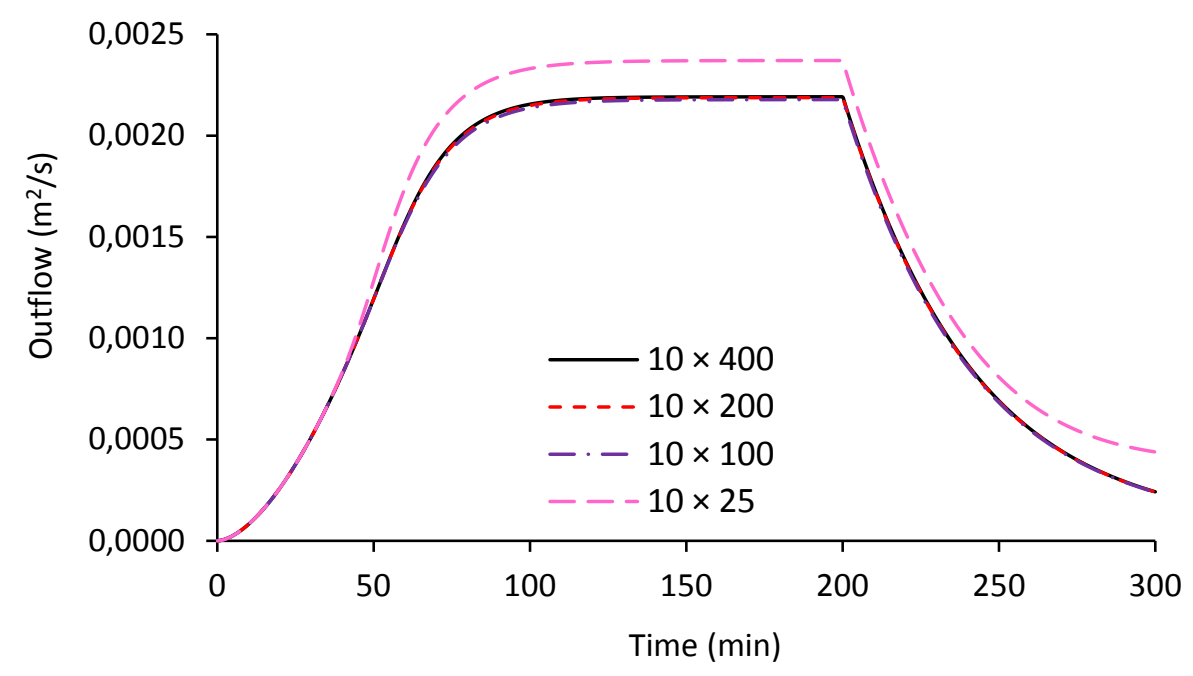

(b)

Fig. 8 Convergence behavior of solutions for one dimensional rainfall-runoff simulation in channel using (a) orthogonal (b) non-orthogonal grids

Subsequently, the CCSS model results were compared with the analytical solution of Gottardi and Venutelli (1993), and with the results of the numerical model proposed by He et al. (2008). Results express acceptable agreement between the three approaches, with excellent agreement between both models.

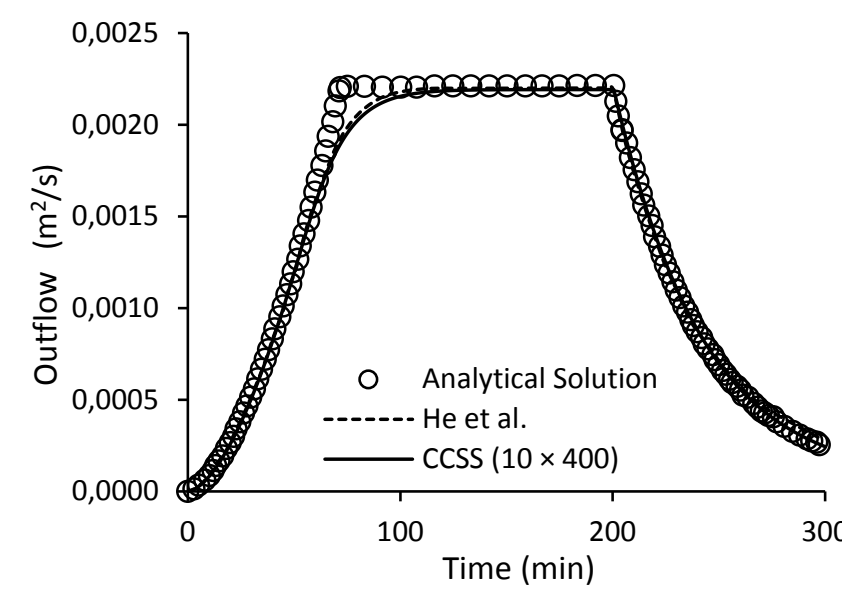

(a)

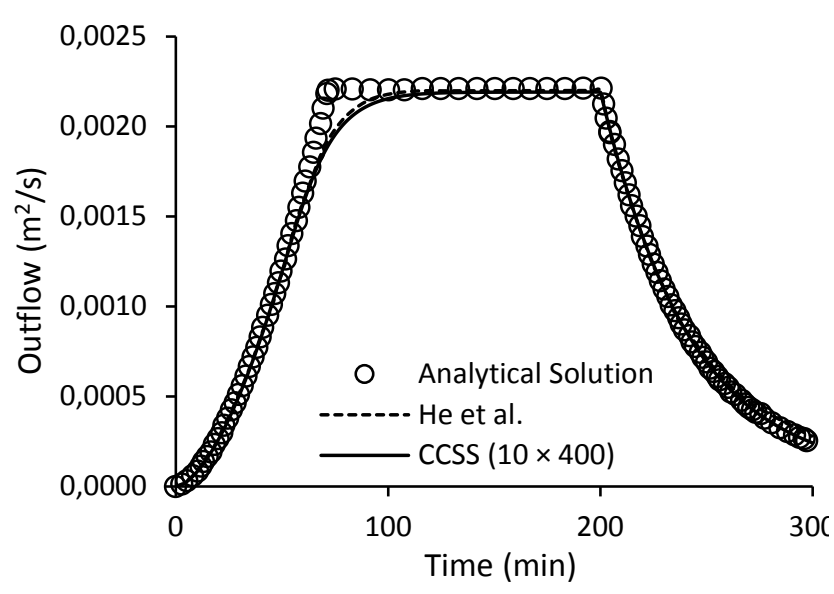

(b)

Fig. 9 Comparison of CCSS, Analytical solution of Gottardi and Venutelli (1993), and simulation results by He et al. (2008) for the simulation of the one dimensional rainfall-runoff test case

Figure 10 shows the time evolution of the mass balance error for this case study. MBE soon reached a steady value. At the moment of rainfall cutoff, MBE peaked and reached a steady value of $10^{-4}-10^{-5}$. 


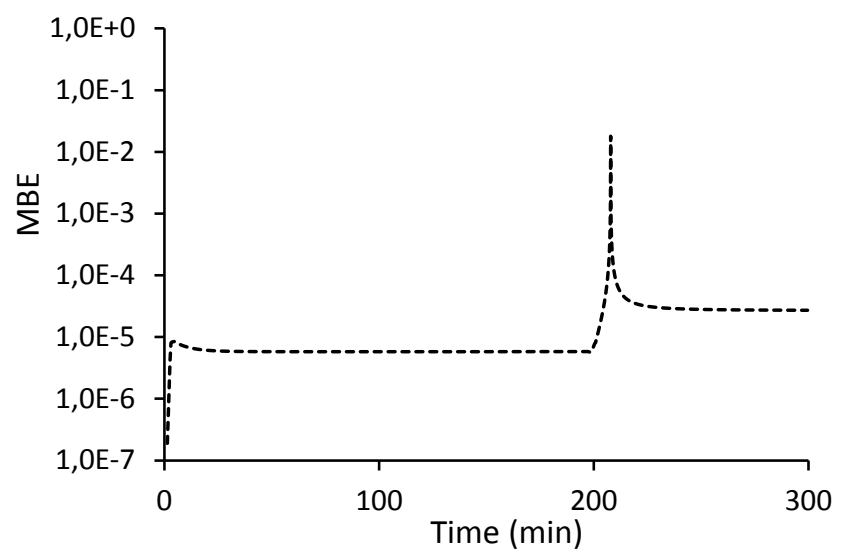

Fig. 10 Time evolution of mass balance error for non-orthogonal grids $(10 \times 400)$ in section 3.2 for evaluation of surface code of CCSS model

Table 3 presents a comparison of calculated CPU time for the test case introduced in this section. In coincidence with Table 2, an increase in CPU time can be observed with mesh density and with the use of the nonorthogonal grids.

Table 3- CPU Times Calculated for Analytical solution of one dimensional rainfall-runoff in an impervious channel (seconds)

\begin{tabular}{|c|c|c|}
\hline Grid & Orthogonal & Non-orthogonal \\
\hline $10 \times 25$ & 1.078 & 1.188 \\
\hline $10 \times 100$ & 31.781 & 32.766 \\
\hline $10 \times 200$ & 202.125 & 212.203 \\
\hline $10 \times 400$ & $1,065.203$ & $1,163.703$ \\
\hline
\end{tabular}

\subsection{Validation of the coupled surface-subsurface model through the simulation of $1 D$ advance in}

\section{border irrigation}

Experimental data obtained by Zerihun et al. (2005a) was used for this validation exercise. These authors conducted irrigation experiments at the Yuma Mesa research farm of the University of Arizona. The size of the experimental borders was $33 \mathrm{~m} \times 177.7 \mathrm{~m}$, with an average slope of $0.1 \%$. They measured advance at 11 regularly spaced stations along the border. Datasets C-4 and C-5 were used in this research. A flow rate of $1.115 \frac{\mathrm{m}^{3}}{\mathrm{~min} . \mathrm{m}}$ was uniformly applied to the borders up to an advance distance of $107.2 \mathrm{~m}$. The van Genuchten soil characteristics are illustrated in Table1 (soil No. 4). Manning roughness coefficient was $0.05 \mathrm{~s} . \mathrm{m}^{-1 / 3}$. The initial condition of surface and subsurface flows were assumed to be $h(x, y, 0)=0 \mathrm{~m}$ and $\theta(x, y, z, 0)=0.067 \mathrm{~cm}^{3} /$ $\mathrm{cm}^{3}$, respectively. Figure 11.a shows the boundary conditions of surface and subsurface flows. Boundary conditions at the surface outlet and at the bottom of the subsurface domain were zero depth gradient and free drainage, respectively. All vertical boundaries were set as no-flow boundary conditions.

In border irrigation the surface and subsurface flows can be assumed to be governed by 1D zero inertia SaintVenant and 1D mixed-form of Richards' equations, respectively. However, the infiltration process is practically two dimensional. Moreover, the 3D shape of the border (the field slope) requires non-orthogonal grids. Figure 9.b presents the $10 \times 201 \times 25$ non-orthogonal grid used for simulation. On the other hand, the uniform inflow applied to the border induces one dimensional surface flow. As a consequence, in order to prevent time-consuming calculations, the 33-meter width was reduced to 0.08-m width. 


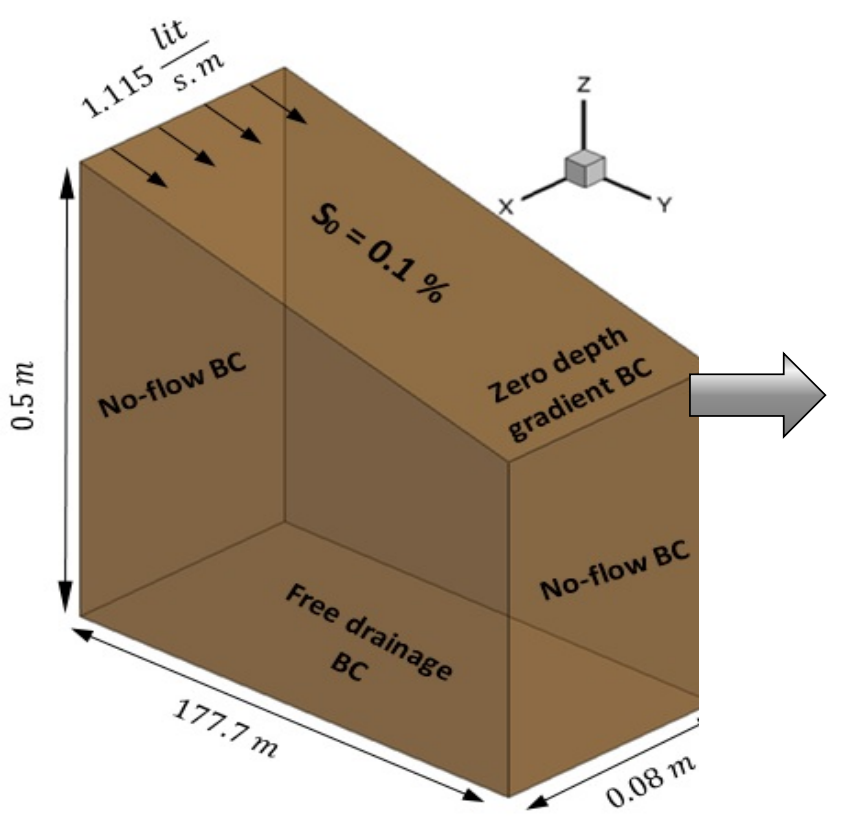

(a)

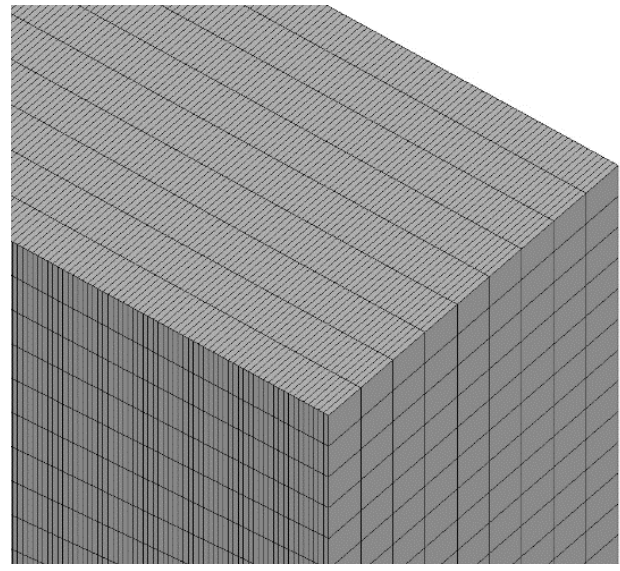

(b)

Fig. 11 (a) Structure and boundary conditions of the solution domain for surface and subsurface flows in Zerihun et al. (2005a) test case along with (b) its corresponding $10 \times 201 \times 25$ non-orthogonal grid

Figure 12 compares the experimental data with the results of simulation by Zerihun et al.'s model (2005a) and the CCSS model. The Root-mean-square error of both simulation models is also presented. The results presented in Figure 12 could imply that the CCSS model performs slightly better than Zerihun et al.'s model (2005a). However, we believe that both models show similar accuracy. This validation case is only based on the advance phase, in which the effect of infiltration can be small compared to the effect of the high inflow rate. Therefore, the performance of these models - whose main difference is the dimensionality of the subsurface equations - cannot be thoroughly assessed through the results depicted in Figure 12.

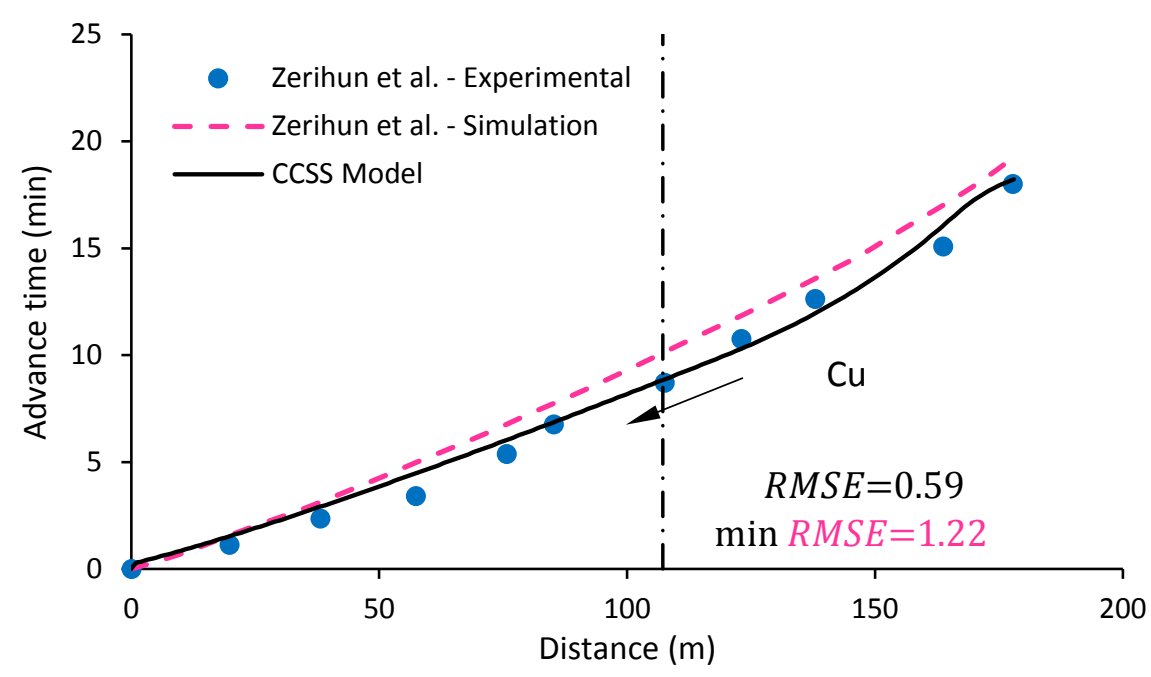

(a) 


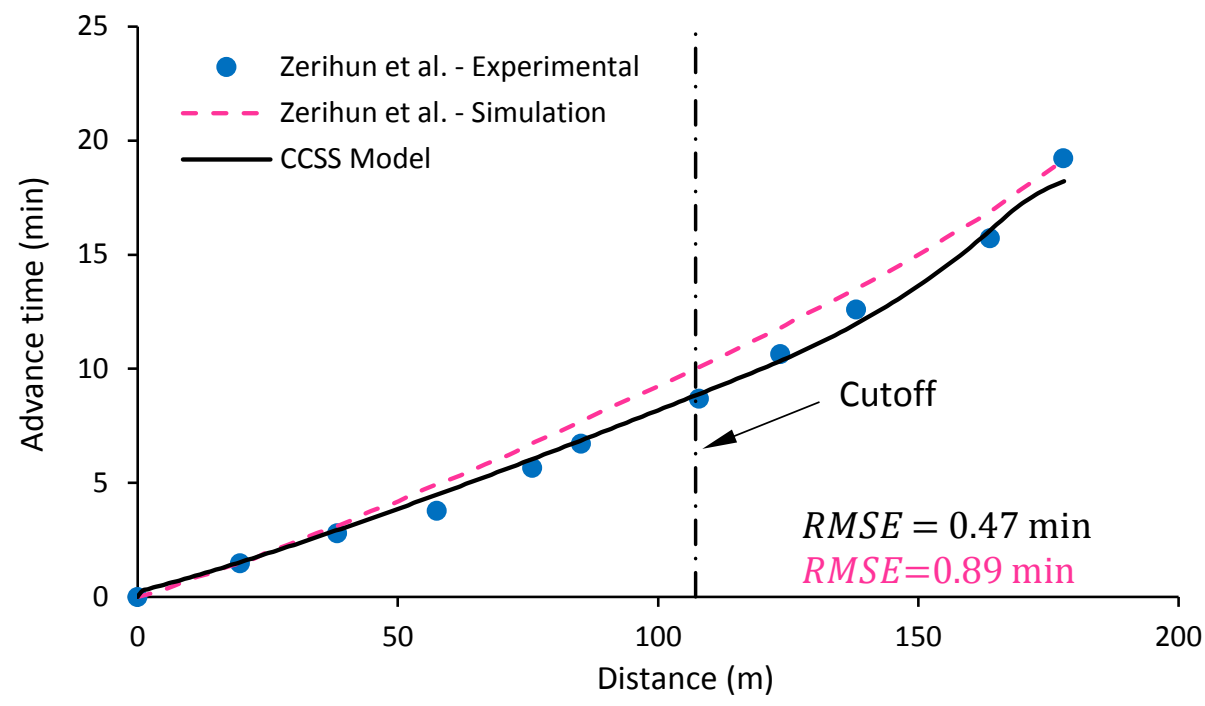

(b)

Fig. 12 Advance phase trajectories simulated by CCSS and Zerihun et al.'s model compared to experimental data for (a) C-4 and (b) C-5 datasets of Zerihun et al. (2005a) along with Root-mean-square error (RMSE)* of each model.

$$
{ }^{*} R M S E=\sqrt{\frac{\left(x_{\text {measure }}-x_{\text {simulation }}\right)^{2}}{n}}
$$

Finally, the mass balance error of the coupled surface-subsurface model reproducing the advance phase of the basin irrigation case is presented in Figure 13. MBE increased during the simulation, approaching a steady value in the order of $10^{-2}$ soon in the simulation process.

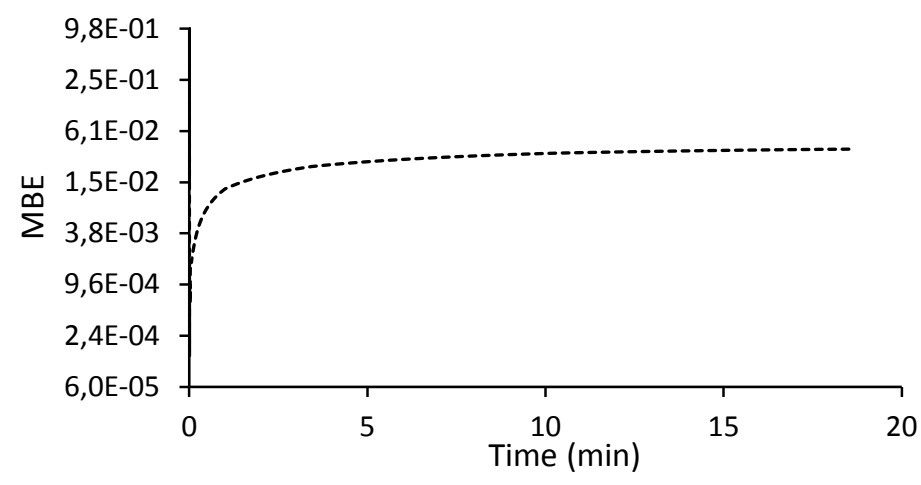

Fig. 13 Time evolution of mass balance error for the test case proposed by Zerihun et al. (2005a) for evaluation of coupled surface-subsurface code of CCSS model.

The largest CPU time was obtained for this test: 154,334 s (about 42 hours). The reason behind the long CPU time is the large linear system resulting from the coupling of 2D overland flow and 3D infiltration equations that were simultaneously solved in a curvilinear coordinate system. Simulation of such complex cases will require additional computational speed through code optimization, the use of faster computation devices and/or parallel programming.

\subsection{Validation: 2D basin irrigation using a Kostiakov infiltration equation}

The CCSS model was further validated with the field experiment conducted by Zapata and Playán (2000). Surface irrigation was applied on an undulated square-shaped basin with an area of $729 \mathrm{~m}^{2}(27 \mathrm{~m} \times 27 \mathrm{~m})$. As the 
available data for this experiment was not suitable to run Richards' equation, in this section the empirical equation of Kostiakov-Lewis was coupled with equation (23).

$Z_{\text {inf }}=K_{k l} \tau^{a_{k l}}+f_{k l} \tau$

Where $Z_{\text {inf }}$ is cumulative infiltration $[L], \tau$ is opportunity time [T], $K_{k l}\left[L . T^{-a_{k l}}\right], a_{k l}[-]$ and $f_{k l}\left[L . T^{-1}\right]$ are empirical coefficients of the Kostiakov-Lewis equation. The constant parameters $K_{k l}, a_{k l}$ and $f_{k l}$ were reported to be $0.0147 \mathrm{~m} / \mathrm{min}^{a_{k l}}, 0.2563$ and $0.0 \mathrm{~m} / \mathrm{min}$, respectively. The Manning roughness coefficient was estimated as $0.4 \mathrm{~s} . \mathrm{m}^{-1 / 3}$. The experimental basin was irrigated from the southwestern corner with a constant discharge of $0.0093 \mathrm{~m}^{3} / \mathrm{s}$ for $90 \mathrm{~min}$. The in-situ observations of advance and recession were recorded in a regular network with $1.5 \mathrm{~m}$ spacing. The topography of the experimental basin in Zapata and Playán (2000) is presented in Figure 14. Brufau et al. (2003) developed a two-dimensional model for the full-hydrodynamic form of the Saint-Venant equations using an upwind-based finite volume scheme with unstructured triangular and quadrilateral computational cells (for the case presented in this paper, they used square shaped computational grids). Their model was based on a cell-centered Godunov-type explicit solution scheme. The temporal and spatial discretization approaches were first-order accurate i.e. backward Euler method for the temporal discretization (the same as CCSS model) and piecewise constant scheme for distribution of dependent variables (CCSS model uses a second-order spatial discretization scheme).

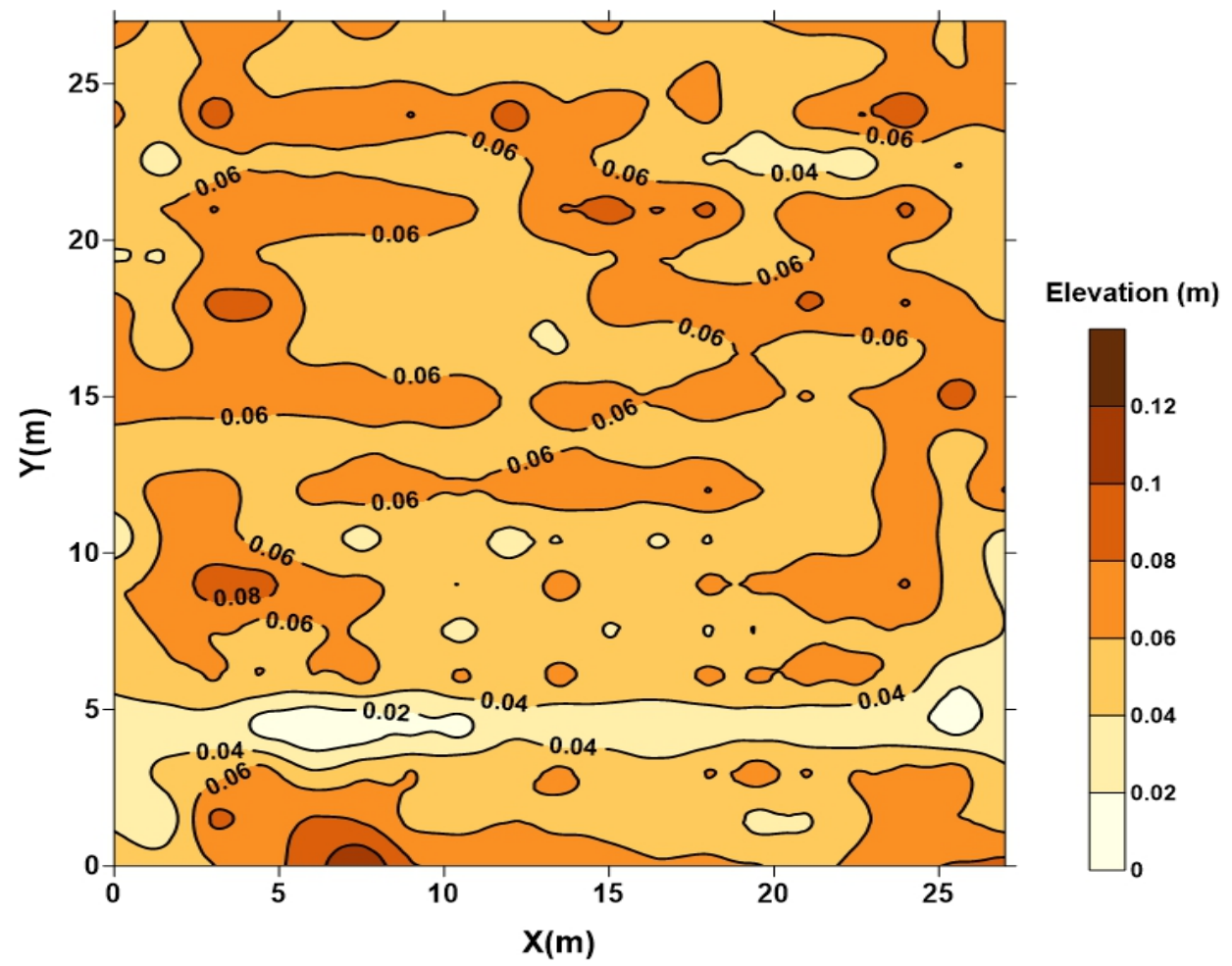

Fig. 14 Field topography of the experimental basin in Zapata and Playán (2000)

A grid density of $100 \times 100\left(\approx 0.27 \times 0.27 \mathrm{~m}^{2}\right)$ was chosen for the simulation of this test case. The advance and recession phase trajectories simulated with CCSS and Brufau et al.'s (2002) model are presented in Figure 15 together with the experimental observations. Brufau et al. (2002) presented their results for two grid sizes of 0.5 and $0.75 \mathrm{~m}$. in this section results of $0.5 \mathrm{~m}$ mesh size is reported as through which more acceptable results were obtained by Brufau et al. (2002). The root mean squared error of each simulation is presented in the Figure. Based on the calculated RMSEs, CCSS model resulted in more accurate simulations. This was more clear during the recession phase, where the RMSE of the CCSS model was almost half of that obtained by Brufau et al.'s (2002) 
model. In the case of the advance phase trajectory (Figure 15-a), the CCSS model performed better than Brufau et al.'s model, particularly in the second half of irrigation advance.

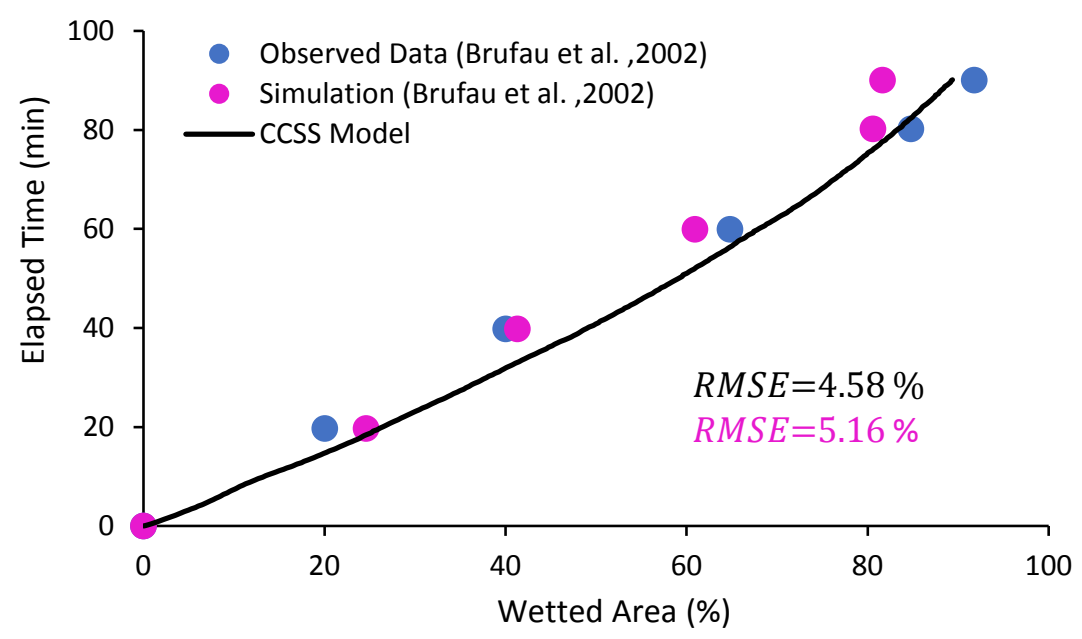

(a)

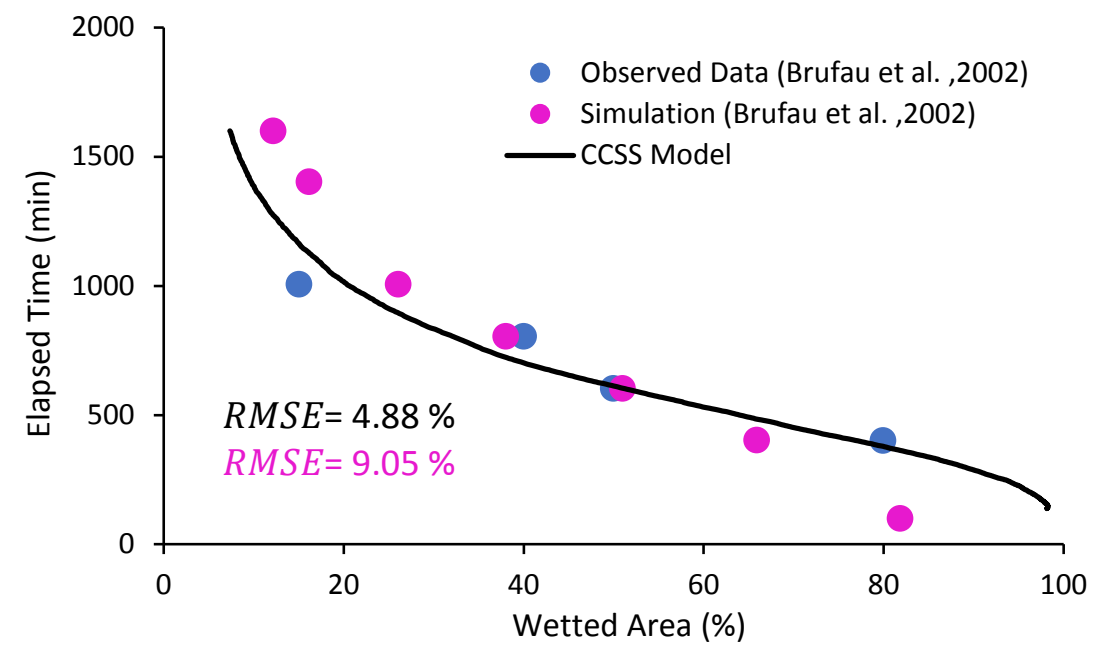

(b)

Fig. 15 (a) Advance and (b) recession trajectories simulated by CCSS model and Brufau et al.'s (2002) model compared to experimental data obtained by Zapata and Playán (2000)

The main reason for the difference between the models in this section may reside in the different order of spatial schemes. CCSS had slightly more accurate results as it employs a second-order accurate spatial scheme. Moreover, a very dense mesh was used for running the CCSS model in this test case to obtain mesh-independent results. On the other hand, Brufau et al. (2003) did not state that the solution presented for their $0.5 \mathrm{~m}$ mesh size was mesh-independent. They might have obtained the same results if they had used $0.27 \mathrm{~m}$ mesh size. Both models performed similarly during the advance phase, while CCSS produced a better simulation of the recession curve. During the advance phase of the irrigation, the role of the neglected terms in the simplified form of Saint-Venant equations used in CCSS is more significant than in the recession phase, in which water is almost stagnant. The inertia terms in Brufau et al.’s model could compensate its first-order spatial accuracy in advance phase. 
The CPU time for a simulated time of 1600 min was 4,514 s. The CPU time obtained by Brufau et al. (2002) for this case was in the order of tenths of minutes with a grid of $0.5 \mathrm{~m}$ spacing and a $500 \mathrm{MHz}$ processor.

\subsection{Application: Numerical simulation of water flow on a closed highly-undulated basin}

In this section, the performance of the CCSS model in the simulation of a point source water flow in a $20 \mathrm{~m} \times$ $20 \mathrm{~m}$ highly-undulated irrigation basin (Figure 16) is presented. Average basin slopes in the $x$ and $y$ directions are 1 and $2 \%$, respectively. The constant inflow rate was $5 \times 10^{-3} \mathrm{~m}^{3} \cdot \mathrm{s}^{-1}$ for $90 \mathrm{~min}$. Soil texture in the basin is clay, as presented in Table 1 (Soil No. 1), and the Manning roughness coefficient is $0.03 \mathrm{~s} . \mathrm{m}^{-1 / 3}$. The initial condition of surface and subsurface domains are $h(x, y, 0)=0 m$ and $\psi(x, y, z, 0)=0.0-z$, respectively. The boundary conditions of the basin were set as no-flow in all directions, including the bottom condition of subsurface flow.

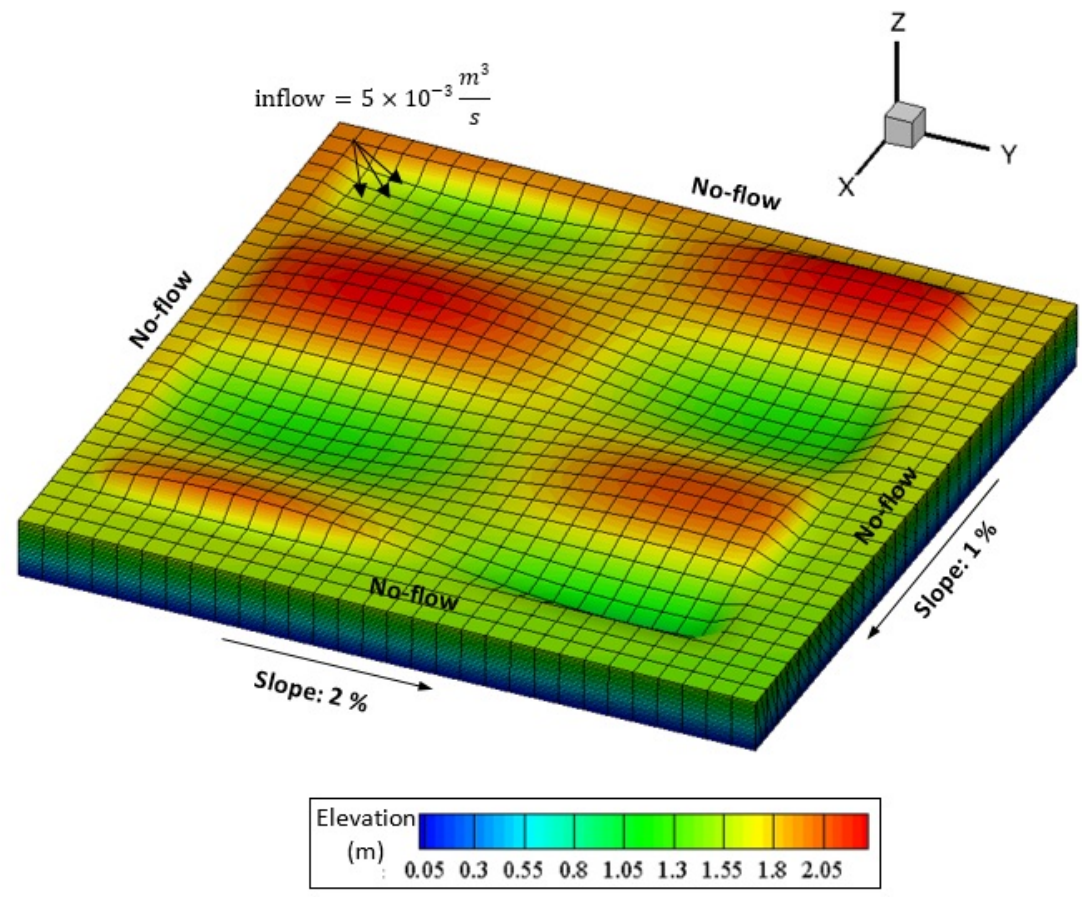

Fig. 16 Highly-undulated basin, presenting the boundary conditions and the non-orthogonal mesh

Surface water flow is presented in Figure 17 at 5, 25, 32, 60, 70 and 90 min after the beginning of irrigation. During the first 25 min water applied through the point source fills the adjacent depression (Figure 17.a and b). Subsequently, it overflows to the next pond in about 30 min (Figure 17.c). Then it finds its way towards the northern boundary. Since this is a no-flow boundary, water flows down to the north-eastern corner of irrigation basin and accumulates at this part due to its low elevation.

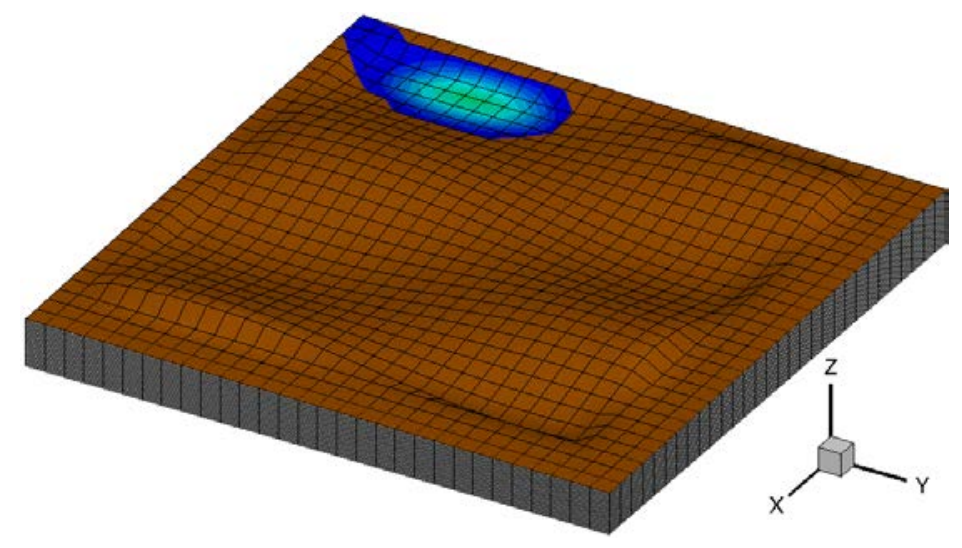


(a)

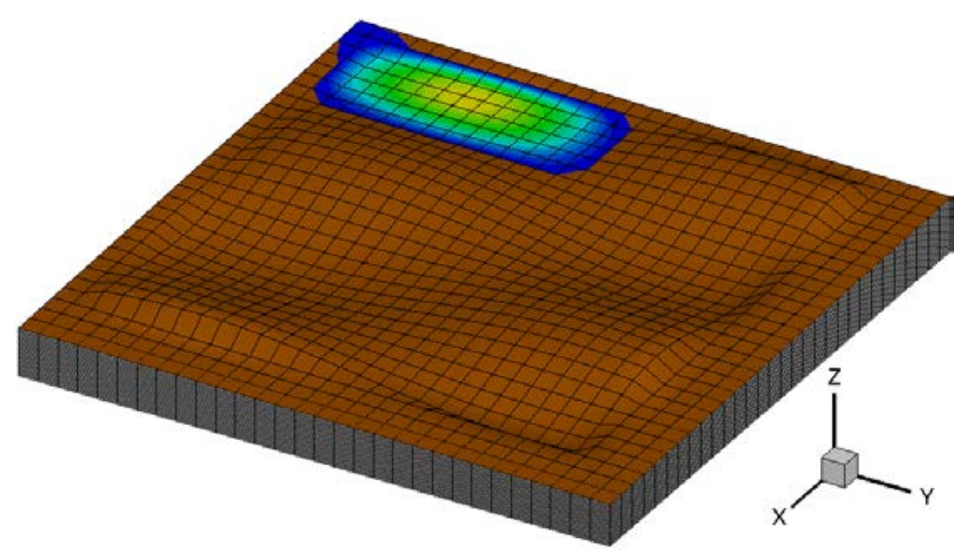

(b)

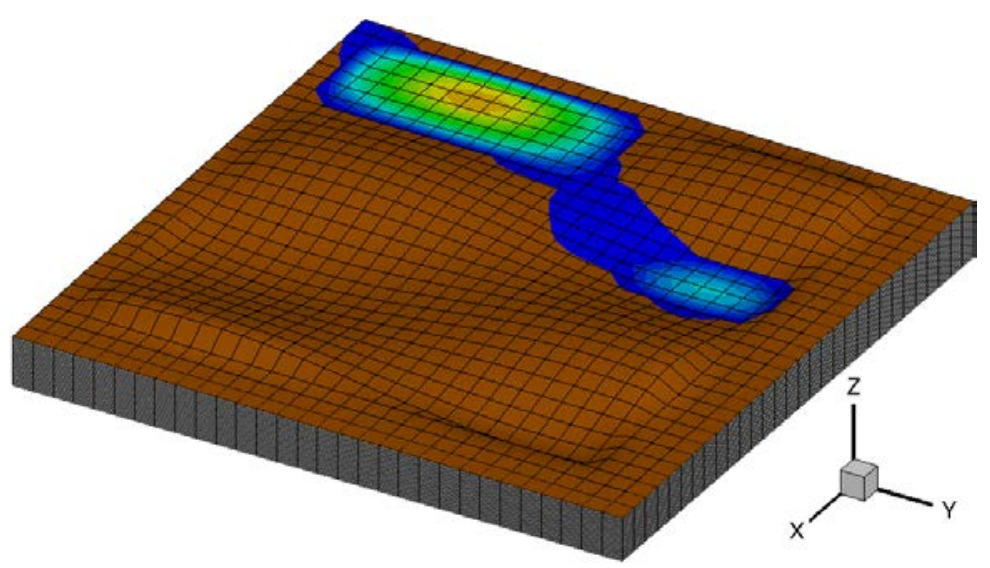

(c)

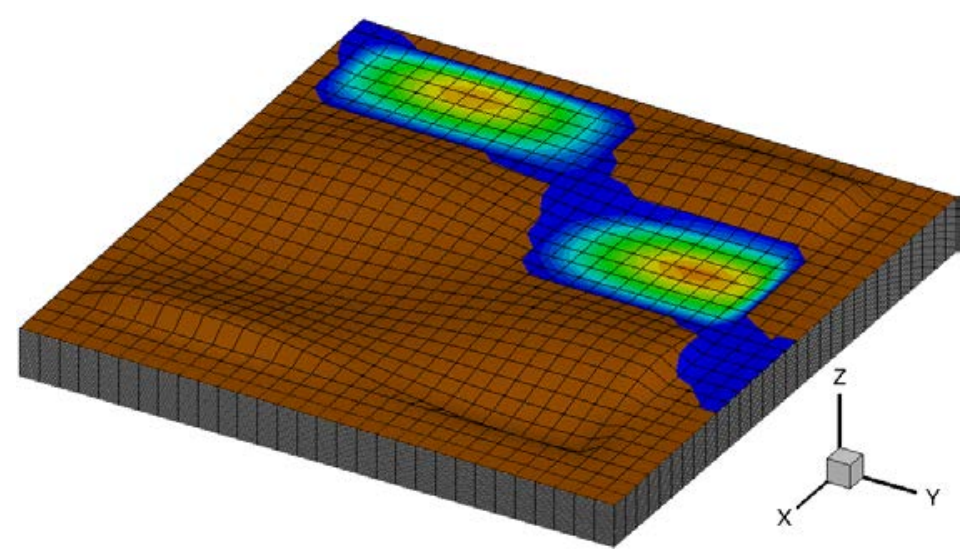

(d) 


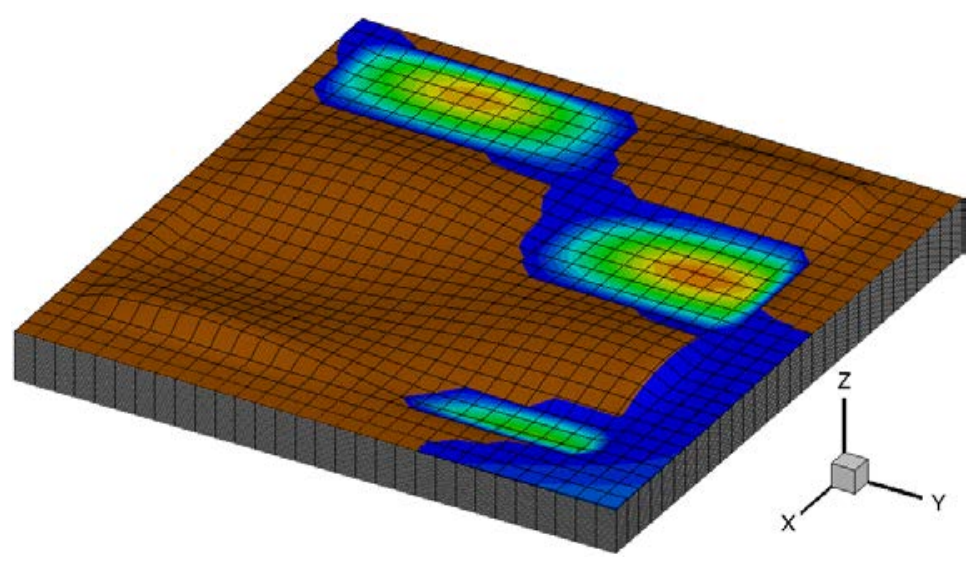

(e)

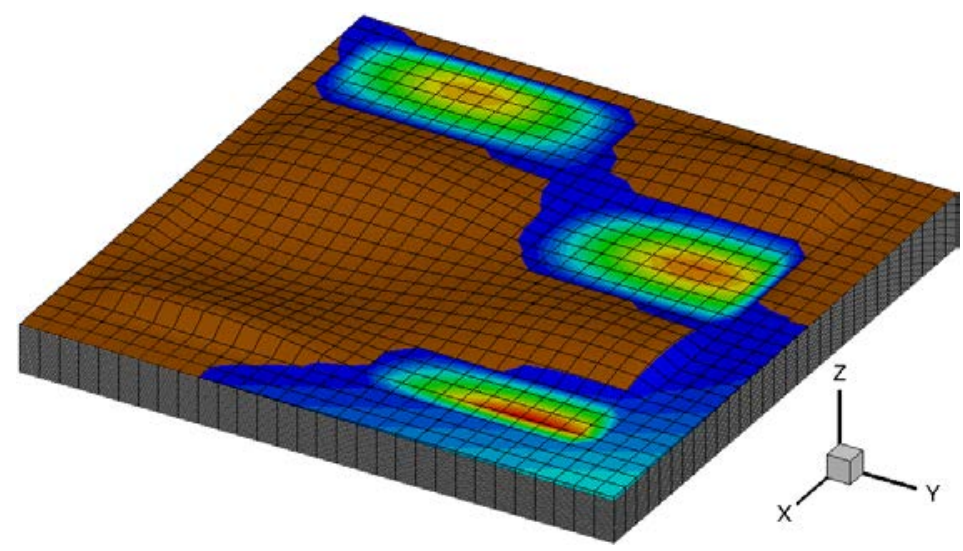

(f)

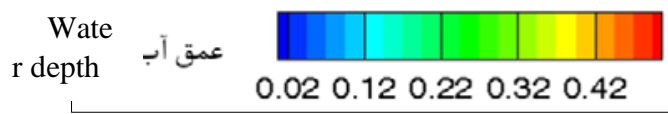

Fig. 17 Water movement on highly-undulated basin after (a) $5 \mathrm{~min}$, (b) $25 \mathrm{~min}$, (c) $32 \mathrm{~min}$, (d) $60 \mathrm{~min}$, (e) $70 \mathrm{~min}$ and (f) $90 \mathrm{~min}$ 


\section{Conclusion}

In this study a coupled surface-subsurface simulation model for basin/border irrigation is proposed. This model employs a finite volume approach to solve the three dimensional mixed-form of Richards' equation coupled with the two dimensional Saint-Venant equations in diffusion wave approximation form. The simulation of water flow on undulated topographies was carried out using a non-orthogonal curvilinear coordinates system. The use of an underrelaxed-modified Picard iteration algorithm for Richards' equation and an underrelaxed Picard iteration algorithm for Saint-Venant equations accompanied with dynamic time stepping resulted in a relatively simple-toimplement, yet robust model. Coupling the surface and subsurface models was obtained with enforcing the continuity of pressure at the interface.

The subsurface and surface models were separately validated. The subsurface code and the HYDRUS-1D software showed adequate agreement for the simulation of one dimensional infiltration within clay, loam and sand soil textures. Surface flow was validated with the analytical solution of Gottardi and Venutelli (1993) as well as the numerical simulation of $\mathrm{He}$ et al. (2008) in the case of one dimensional rainfall-runoff simulation through a constant rainfall rate on an impermeable channel. For both orthogonal and non-orthogonal grids the meshindependent simulations showed adequate agreement with analytical and previous numerical solutions. The proposed model was then validated with two sets of experimental border and basin irrigation data. The proposed model showed similar performance to a one dimensional surface-subsurface model. Comparison of CCSS simulations with experimental irrigation data on an undulated basin showed consistent results. Root mean squared error of CCSS simulations compared with that of previous simulation efforts showed small decreases in both the advance and recession phases. The mass balance error showed acceptable, decreasing/constant rates in all three validation cases. The increase of CPU time with grid size showed a potential exponent of 1.50. CPU time strongly varied with soil type, and increased with non-orthogonality at strongly variable rates (between 6 and 828\%, depending on soil type).

The complete CCSS model was applied to simulate point source irrigation in a highly-undulated basin. Simulation results were compatible with the expected outcome. Flow depth was adequately simulated in this demanding case study.

This paper illustrates the application of the proposed model to the simulation of experiments available in the literature. Further development of the model will require specific experiments in different soil types, mesh configurations and other types of surface irrigation systems, such as furrow irrigation. Additionally, the processes of soil water redistribution and evapotranspiration could be included in the model to produce a more comprehensive simulation tool providing operational, accurate answers to water management questions in irrigated agriculture. An increase in computational speed will be required in the phase of model exploitation. 


\section{References}

An H, Ichikawa Y, Tachikawa Y, Shiiba M (2010) Three

flow modeling with nonorthogonal grids using a coordinate transformation method. Water Resources Research 46. DOI:10.1029/2009WR009024

An H, Ichikawa Y, Tachikawa Y, Shiiba M (2011) A new Iterative Alternating Direction Implicit (IADI) algorithm for multi-dimensional saturated-unsaturated flow. Journal of Hydrology 408:127-139, DOI:10.1016/j.jhydrol.2011.07.030

An H, Ichikawa Y, Tachikawa Y, Shiiba M (2012) Comparison between iteration schemes for threedimensional coordinate-transformed saturated-unsaturated flow model. Journal of Hydrology 470:212226. DOI:10.1016/j.jhydrol.2012.08.056

An H, Yu S (2014) Finite volume integrated surface Resources Research 50:2312-2328. DOI:10.1002/2013WR013828

Bautista E, Zerihun D, Clemmens AJ, Strelkoff T (2010) External iterative coupling strategy for surfacesubsurface flow calculations in surface irrigation. Journal of Irrigation and Drainage Engineering 136:692-703. DOI:10.1061/(ASCE)IR.1943-4774.0000248

Brufau P, García-Navarro P, Playán E, Zapata N (2002) Numerical modeling of basin irrigation with an upwind scheme. Journal of irrigation and drainage engineering 128:212-223. DOI:10.1061/(ASCE)07339437(2002)128:4(212)

Clemmens AJ (1979) Verification of the zero-inertia model for border irrigation. Transactions of the ASAE. 22:1306-1309. DOI:10.13031/2013.35203

Clemmens AJ, Dedrick AR (1994) Irrigation Techniques and Evaluations. In: Management of Water Use in Agriculture. Advanced Series in Agricultural Sciences. Springer Berlin Heidelberg, Germany, pp 64103.

Dong Q, Xu D, Zhang S, Bai M, Li Y (2013) A hybrid coupled model of surface and subsurface flow for surface irrigation. Journal of Hydrology 500:62-74. DOI:10.1016/j.jhydrol.2013.07.018

Durbin T, Delemos D (2007) Adaptive underrelaxation of Picard iterations in ground water models. Ground water 45:648-651. DOI:10.1111/j.1745-6584.2007.00329.x

Gottardi G, Venutelli M (1993) A control-volume finite-element model for two-dimensional overland flow. Advances in water resources 16:277-284. DOI:10.1016/0309-1708(93)90019-C

He Z, Wu W, Wang SS (2008) Coupled finite-volume model for 2D surface and 3D subsurface flows. Journal of Hydrologic Engineering 13:835-845. DOI:10.1061/(ASCE)1084-0699(2008)13:9(835)

Huang K, Mohanty B, van Genuchten MT (1996) A new convergence criterion for the modified Picard iteration method to solve the variably saturated flow equation. Journal of Hydrology 178:69-91. DOI: 10.1016/0022-1694(95)02799-8

Khanna M, Malano HM, Fenton JD, Turral H (2003a) Two-dimensional simulation model for contour basin layouts in South East Australia. I: rectangular basins. Journal of irrigation and drainage engineering 129:305-316. DOI: 10.1061/(ASCE)0733-9437(2003)129:5(305)

Khanna M, Malano HM, Fenton JD, Turral H (2003b) Two-dimensional simulation model for contour basin layouts in southeast Australia. II: irregular shape and multiple basins. Journal of irrigation and drainage engineering 129:317-325. DOI:10.1061/(ASCE)0733-9437(2003)129:5(317)

Khanna M, Malano HM (2006) Modelling of basin irrigation systems: A review. Agricultural water management 83:87-99. DOI:10.1016/j.agwat.2005.10.003

Kosugi K (2008) Comparison of three methods for discretizing the storage term of the Richards equation. Vadose Zone Journal 7:957-965. DOI:10.2136/vzj2007.0178

Lal AW (1998) Weighted implicit finite-volume model for overland flow. Journal of Hydraulic Engineering 124:941-950. DOI:10.1061/(ASCE)0733-9429(1998)124:9(941)

Paniconi C, Putti M (1994) A comparison of Picard and Newton iteration in the numerical solution of multidimensional variably saturated flow problems. Water Resources Research 30:3357-3374. DOI:10.1029/94WR02046

Peaceman DW, Rachford J, Henry H (1955) The numerical solution of parabolic and elliptic differential equations. Journal of the Society for Industrial and Applied Mathematics 3:28-41. DOI: $10.1137 / 0103003$

Perrens S, Watson K (1977) Numerical analysis of two - diratemsional infilt Resources Research 13:781-790. DOI:10.1029/WR013i004p00781

Playán E, Faci J, Serreta A (1996) Modeling microtopography in basin irrigation. Journal of irrigation and drainage engineering 122:339-347. DOI:10.1061/(ASCE)0733-9437(1996)122:6(339) 
Playán E, Walker WR, Merkley G (1994a) Two-dimensional simulation of basin irrigation. I: Theory. Journal of irrigation and Drainage Engineering 120:837-856. DOI:10.1061/(ASCE)07339437(1994)120:5(837)

Playán E, Walker WR, Merkley G (1994b) Two-dimensional simulation of basin irrigation. II: Applications. Journal of irrigation and Drainage Engineering 120:857-870. DOI:10.1061/(ASCE)07339437(1994) 120:5(857)

Richards LA (1931) Capillary conduction of liquids through porous mediums. Physics 1:318-333. DOI:http://dx. doi.org/10.1063/1.1745010

Schaap MG, Leij FJ, van Genuchten MT (2001) ROSETTA: a computer program for estimating soil hydraulic parameters with hierarchical pedotransfer functions. Journal of hydrology 251:163-176. DOI: 10.1016/S 0022-1694(01)00466-8

Schmitz GH, Seus GJ (1989) Analytical model of level basin irrigation. Journal of irrigation and drainage engineering 115:78-95. DOI:10.1061/(ASCE)0733-9437(1989)115:1(78)

Šimůnek J (2005) Models of water flow and solute transport in the unsaturated zone. Encyclopedia of hydrological sciences. DOI:10.1002/0470848944.hsa080

Šimůnek J, Šejna M, Saito H, Sakai M, van Genuchten MT (2013) The Hydrus-1D Software Package for Simulating the Movement of Water, Heat, and Multiple Solutes in Variably Saturated Media, Version 4.17, HYDRUS Software Series 3. Department of Environmental Sciences, University of California Riverside, Riverside, California, USA, pp. 342.

Singh V, Bhallamudi SM (1997) Hydrodynamic modeling of basin irrigation. Journal of irrigation and Drainage Engineering 123:407-414. DOI:10.1061/(ASCE)0733-9437(1997)123:6(407)

Strelkoff T, Souza F (1984) Modeling effect of depth on furrow infiltration. Journal of irrigation and drainage engineering 110:375-387. DOI:10.1061/(ASCE)0733-9437(1984)110:4(375)

Strelkoff TS, Tamimi AH, Clemmens AJ (2003) Two-dimensional basin flow with irregular bottom configuration. Journal of irrigation and drainage engineering 129:391-401. DOI:10.1061/(ASCE)07339437(2003)129:6(391)

Thompson JF, Warsi ZU, Mastin CW (1985) Numerical grid generation: foundations and applications vol 45. North-holland, Amsterdam

Van Dam JC, Feddes RA (2000) Numerical simulation of infiltration, evaporation and shallow groundwater levels with the Richards equation. Journal of Hydrology 233:72-85. DOI: 10.1016/S00221694(00)00227-4

van Genuchten MT (1980) A closed-form equation for predicting the hydraulic conductivity of unsaturated soils. Soil science society of America journal 44:892-898. DOI:10.2136/sssaj1980.03615995004400050002x

Walker WR, Humpherys AS (1983) Kinematic-wave furrow irrigation model. Journal of Irrigation and Drainage Engineering 109:377-392. DOI:10.1061/(ASCE)0733-9437(1983)109:4(377)

Weeks SW, Sander GC, Braddock RD, Matthews CJ (2004) Saturated and unsaturated water flow in inclined porous media. Environmental Modeling and Assessment 9:91-102. DOI:10.1023/B:ENMO.000003 2095.32056.e2

Weill S, Mouche E, Patin J (2009) A generalized Richards equation for surface/subsurface flow modelling. Journal of hydrology 366:9-20. DOI:10.1016/j.jhydrol.2008.12.007

Xu D, Zhang S, Bai M, Li Y, Xia Q (2013) Two-dimensional coupled model of surface water flow and solute transport for basin fertigation. Journal of Irrigation and Drainage Engineering 139:972-985. DOI:10.1061/(ASCE)IR.1943-4774.0000645

Zapata N, Playán E (2000) Simulating elevation and infiltration in level-basin irrigation. Journal of Irrigation and Drainage Engineering 126:78-84. DOI:10.1061/(ASCE)0733-9437(2000)126:2(78)

Celia MA, Bouloutas ET, Zarba RL (1990) General mass-conservative numerical solution for the unsaturated flow equation. Water Resources Research 26:1483-1496.

Zerihun D, Furman A, Warrick A, Sanchez CA (2005a) Coupled surface-subsurface flow model for improved basin irrigation management. Journal of irrigation and drainage engineering 131:111-128. DOI:10.1061 /(ASCE)0733-9437(2005)131:2(111)

Zerihun D, Furman A, Warrick A, Sanchez CA (2005b) Coupled Surface-Subsurface Solute Transport Model for Irrigation Borders and Basins. I. Model Development. Journal of irrigation and drainage engineering 131:396-406. DOI:10.1061/(ASCE)0733-9437(2005)131:5(396)

Zhang S, Bai M, Xia Q, Yu H (2016) Efficient Simulation of Surface Water Flow in 2D Basin Irrigation Using Zero-Inertia Equations. Journal of Irrigation and Drainage Engineering 143. DOI:10.1061/(ASCE)IR. $\underline{1943-4774.0001121}$ 
Zhang S, Xu D, Bai M, Li Y (2014a) Dimensional splitting finite-volume method for two-dimensional surface water flow model in basin irrigation. Journal of Irrigation and Drainage Engineering 140. DOI:10.1061/ (ASCE)IR.1943-4774.0000698

Zhang S, Xu D, Bai M, Li Y (2014b) Two-dimensional surface water flow simulation of basin irrigation with anisotropic roughness. Irrigation Science 32:41-52. DOI:10.1007/s00271-013-0410-4

Zhang S, Xu D, Bai M, Li Y, Xia Q (2014c) Two-dimensional zero-inertia model of surface water flow for basin irrigation based on the standard scalar parabolic type. Irrigation Science 32:267-281. DOI: 10.1007/s00 271-014-0429-1 